Research Article

\title{
Strategic Customer Behavior and Pricing Strategy Based on the Horizontal Differentiation of Products
}

\author{
Yang Zhao $\mathbb{D D}^{1}{ }^{1}$ Guojun Ji, ${ }^{2,3}$ Yue Jiang $\mathbb{D}^{4},{ }^{4}$ and Xiaopei Dai ${ }^{5}$ \\ ${ }^{1}$ School of Management, Shandong Technology and Business University, Yantai 264005, China \\ ${ }^{2}$ Collaborative Innovation Center for Peaceful Development of Cross-Strait Relations, Xiamen 361005, China \\ ${ }^{3}$ School of Management, Xiamen University, Xiamen 361005, China \\ ${ }^{4}$ School of Management, Fujian University of Technology, Fuzhou 350118, China \\ ${ }^{5}$ Business School of Hunan Normal University, Changsha 410081, China \\ Correspondence should be addressed to Yang Zhao; zhaoyang2016yt@163.com
}

Received 15 August 2019; Revised 23 November 2019; Accepted 29 November 2019; Published 18 January 2020

Academic Editor: Bruno G. M. Robert

Copyright (C) 2020 Yang Zhao et al. This is an open access article distributed under the Creative Commons Attribution License, which permits unrestricted use, distribution, and reproduction in any medium, provided the original work is properly cited.

\begin{abstract}
Manufacturers produce products with horizontal differences to meet different needs of customers. This paper compares the influence of three different sales channels on strategic customers' choice and the pricing strategy of products with horizontal differentiation. The results show that the strategic customers whose willingness to pay (WTP) is close to 1 will buy highperformance products and whose WTP is close to 0 will not purchase any kind of products in the two dual-channel models. If the manufacturers adopt dual channel to sell products with horizontal differences, the retailers agree that the manufacturers sell highperformance products in the traditional channel and sell low-performance products in the electronic channel. In dual-channel supply chain model I, the higher the satisfaction of high-performance products and the lower the satisfaction of low-performance products, the more conducive to the retailers.
\end{abstract}

\section{Introduction}

In recent years, the rapid development of the logistics industry and electronic channels has brought new opportunities to the traditional manufacturers. The electronic channel acquaints the customer with the characteristics, price, and third-party evaluations of the products. Customers can obtain product information conveniently through the electronic channel. The reduced cost of searching for information and discrepant channel price lead to free-rider behavior between channels. The customers acquire information from the retailer and then purchase products at low prices in the electronic channel, which provides limited service. This is called free-rider behavior. Free-rider behavior between channels can operate in both directions. Customers can also search product information in the electronic channel, such as performance parameters, and choose to purchase in the retail channel [1]. Strategic customers select the buying channel according to the surplus utility maximization, known as the channel behavior of strategic customers. The consequences of widespread freerider behavior are serious because free-rider behavior does not achieve the group goal or the optimal goals. And the free-rider behavior does not fully utilize limited resources. More seriously, this behavior can spread among customers and damage retailer profits [2].

How to alleviate the conflicts between channels has become a hot topic among scholars. A manufacturer can sell the same products in electronic and retail channels and also sell two kinds of products, which have different performances. In the multichannel, product differentiation strategy is not only the key factor in merchants' game but also the role of alleviating channel conflicts has been concerned by scholars at home and abroad. In the existing product differentiation model, the high differentiation will weaken the market competition and break the original stable Nash equilibrium [3-5]. The manufacturer producing two differentiated products can sell in these models as follows: first, 
the single retail channel sells these differentiated products. Second, the manufacturer sells the lower performance product in its own electronic channel and sells the higher performance product in the retail channel; we call this dualchannel model I. Third, the manufacturer sells the higher performance product in its own electronic channel and sells the lower performance product in the retail channel; we call this dual-channel model II.

In this paper, we seek to get optimal prices in the above three models and analyze how the satisfaction of strategic customers with differentiated products affects the optimal decisions. To answer these questions, we review the related literature and introduce our research method as follows.

\section{Literature Review}

For our research, the literature review can be divided into three parts: the product differentiation, the dual-channel, and the strategic customer behavior. We elaborate on them below:

(a) Products differentiation: initially, the most researches focused on the two manufacturers selling differentiated products through traditional channels. Gabszewicz and Thisse established a duopoly model and pointed out that when the income gap among customers is large enough, the two enterprises will expand the gap in product quality to avoid fierce price competition and improve their respective profits [6]. Shake and Sutton further pointed out that when there were only two manufacturers in the market, manufacturers producing high-quality products would make higher profits [7]. Moorthy and Png found that in order to avoid the market share of high-quality products being plundered by low-quality products, manufacturers would introduce high-quality products first and then lowquality products [8]. At the same time, some scholars found that when the market share of low-quality products is larger or the high-quality products have substitutes, they will first introduce low-quality products and then high-quality products [9, 10]. Zhao et al. discussed the pricing strategy and product differentiation strategy, and the pricing strategy is easier to change, belonging to the short-term market behavior, and differentiation strategy belongs to the long-term market behavior [11]. Liu and Zhang studied a dynamic pricing competition model which retailers offer vertically differentiated products to strategic customers, focusing on the role of product performance and the value of price commitment [12]. When manufacturers produce similar or differentiated products and sell them at different prices in diversified markets, Kim and Bell concluded that revenue managers and supply-chain coordinators set prices and product quantities according to the costs of each market segment [13].

(b) Differentiated products in dual channel: With the change of sales patterns, Yan found when customers are insensitive to prices, the greater the product differentiation, the more conducive to increase corporate profits [14]. Chen and Liu pointed out that greater degree of product differentiation can bring higher profits to the manufacturers who dominate the game in the dual-channel supply chain [15]. Andaluz and Jarne defined a demand model about differentiated products and found that if the complementary products and substituted products exist, the stability of Nash equilibrium will improve with the increase of the product independence [16]. Freyberger develops asymptotic theory in differentiated product demand systems according to a small number of products and a large number of markets [17]. However, few of the above literatures deal with the strategic customers. Chen et al. concerned price and quality decisions in dual-channel supply chains and discussed the effects of the quality sensitivity parameters of different channels on price and product quality, as well as profits and consumer surplus [18]. Huang et al. considered the parallel importers (PIs) and developed a game-theoretic model for a dual-channel supply chain, and the results suggested that the manufacturer should choose to design the lower quality products to weaken the PI's competitiveness [19].

(c) Strategic customer behavior: in the dual-channel supply chain, the free-rider behavior of customers is actually a kind of strategic behavior. When the sales services and the sales offered by retailers themselves can be separated, and the different retailers provide different services and prices, then this will result in the free-rider behavior. It can damage the profits of the retailer that provide high-quality services [20]. Cubitt et al. analyzed how social preferences affect free-rider motivation and behavior directly or indirectly. Some scholars design the experiment about free-rider behavior to test the effectiveness of the control mechanism [21]. For example, Ertan et al. studied the punishment mechanism [22], Coats et al. researched the compensation mechanism [23], and Kiyonari and Barclay discussed the reward mechanism [24]. The literature above finds that punishment and reward mechanisms can significantly control the free-rider behavior, while the compensation mechanism reduces free riding only in simultaneous institution. Scholars study the problems of information free-rider behavior and of coordinating contract design between a single manufacturer and retailer. For example, Ding and Liu discussed the optimal prices when free-rider behavior exists within centralized and decentralized structures and found the revenue-sharing contract can achieve dual-channel supply-chain coordination [25].

Huang and Yang pointed out that retailers set different prices during normal and discounted sales periods and influence strategic customer behavior through capacity selection. Strategic customers choose the best purchase opportunity according to price and capacity [26]. Bi et al. held that strategic customer 
behavior would reduce the additional revenue obtained through dynamic pricing [27]. Li and Wei studied the strategic customer behavior and the price guarantee contract. The results show that the strategic customer behavior will reduce the supply-chain profits and the price guarantee contract can alleviate but cannot eliminate the strategic customer behavior completely [28]. Correa et al. found that retailers can publish product prices ahead of time to alleviate strategic customer behavior [29]. Ji et al. studied the effect of strategic customer behavior on the performance of manufacturers and retailers. The results show that strategic customers are more inclined to the retailerdominated market with lower prices. If enterprises face up to strategic customer behavior, they can achieve a win-win situation [30]. Chen constructed a supplychain coordination model for short-life-cycle products based on strategic customer behavior from the perspective of rational expected utility theory and prospect theory [31]. Zhang et al. studied the retailer's return policy with strategic customers and pointed out that only when the return channel is more efficient, the retailer accepting the returned products and selling them in the normal sales period can bring higher profits [32]. Some scholars begin to integrate strategic customer behavior and product differentiation. Parlaktuk studied the value of manufacturers adopting product differentiation strategy based on strategic customer behavior [33]. Yang and Ji discussed the intertemporal choice of strategic customers between the original products of the advanced market entrants and the imitated products of the late market entrants [34].

The above literatures either focus on the combination of dual channel and product differentiation, or consider the combination of the strategic customer behavior and product differentiation and rarely studied product differentiation strategy in dual channel based on strategic customer behavior. And most of the literatures analyze vertical differentiation strategy, which is products having quality differences. However, this paper discusses the product horizontal differences, which is put forward by Hotelling, i.e., some customers prefer high-performance products, some customers feel that low-performance products can meet their needs, and the products themselves do not exhibit quality differences. Under the background of horizontal differences, which is expressed by high-performance product $H$ and low-performance product $L$, this paper studies the choice behavior of strategic customers and the corresponding optimal pricing strategy in the single traditional channel and dual channel, respectively. The purpose is to make manufacturers and retailers understand strategic customer behavior deeply and better design sales channels and pricing strategy.

\section{Models}

3.1. Sell Products $H$ and $L$ in the Single Retail Channel. This model includes one manufacturer, one retailer, and strategic customers. We use $H$ to express the higher performance products and $L$ to express the lower performance products. The manufacturer sells products $H$ and $L$ in a single retail channel. The sales process is shown in Figure 1. Assume $P_{H}$ represents the price of higher performance products and $P_{L}$ represents the price of lower performance products, and $P_{H}>P_{L}$.

The willingness to pay of strategic customers is represented by $x \in(0,1)$, subjected to uniform distribution [35]. The satisfaction of strategic customers about products $H$ is denoted by $\theta_{H}$ and about products $L$ is denoted by $\theta_{L}$. The parameters should meet the criteria $0<\theta_{L}<\theta_{H}<1$. The utility function is $U_{H}=\theta_{H} x-P_{H}$ for buying the higher performance products and $U_{L}=\theta_{L} x-P_{L}$ for buying the lower performance products. The selection function of strategic customers is $V=$ $\max \left\{U_{H}, U_{L}, 0\right\}=\max \left\{\theta_{H} x-P_{H}, \theta_{L} x-P_{L}, 0\right\}$, and then we can get the following expression by comparative analysis:

$$
V= \begin{cases}\theta_{H} x-P_{H}, & x \geq \frac{P_{H}-P_{L}}{\theta_{H}-\theta_{L}}, x \geq \frac{P_{H}}{\theta_{H}}, \\ \theta_{L} x-P_{L}, & x \leq \frac{P_{H}-P_{L}}{\theta_{H}-\theta_{L}}, x \geq \frac{P_{L}}{\theta_{L}}, \\ 0, & x \leq \frac{P_{H}}{\theta_{H}}, x \leq \frac{P_{L}}{\theta_{L}} .\end{cases}
$$

When the parameters meet the condition $\left(P_{L} / \theta_{L}\right) \leq\left(P_{H} / \theta_{H}\right)$, i.e., $\left(P_{H}-P_{L}\right) /\left(\theta_{H}-\theta_{L}\right) \geq\left(P_{H} / \theta_{H}\right) \geq$ $\left(P_{L} / \theta_{L}\right)$, the expression (1) can be derived as follows:

$$
V= \begin{cases}\theta_{H} x-P_{H}, & x \geq \frac{P_{H}-P_{L}}{\theta_{H}-\theta_{L}}, \\ \theta_{L} x-P_{L}, & \frac{P_{L}}{\theta_{L}} \leq x \leq \frac{P_{H}-P_{L}}{\theta_{H}-\theta_{L}}, \\ 0, & x \leq \frac{P_{L}}{\theta_{L}} .\end{cases}
$$

When the parameters meet the condition $\left(P_{L} / \theta_{L}\right) \geq$ $\left(P_{H} / \theta_{H}\right)$, i.e., $\left(P_{H}-P_{L}\right) /\left(\theta_{H}-\theta_{L}\right) \leq\left(P_{H} / \theta_{H}\right) \leq\left(P_{L} / \theta_{L}\right)$, the expression (1) is changed into (3). The strategic customers will not purchase the lower performance products $L$ :

$$
V= \begin{cases}\theta_{H} x-P_{H}, & x \geq \frac{P_{H}}{\theta_{H}}, \\ 0, & x \leq \frac{P_{H}}{\theta_{H}} .\end{cases}
$$

Lemma 1. The strategic customers can select to buy the lower performance products $L$, when $0 \leq\left(P_{L} / \theta_{L}\right) \leq\left(P_{H} / \theta_{H}\right) \leq$ $\left(P_{H}-P_{L}\right) /\left(\theta_{H}-\theta_{L}\right) \leq 1$.

The selections of strategic customers under expression (2) are discussed, and the details are illustrated in Figure 2.

The number of strategic customers that choose to buy the higher performance products is $Q^{H}=\int_{\left(\left(P_{H}-P_{L}\right) /\left(\theta_{H}-\theta_{L}\right)\right)}^{1} \mathrm{~d} x=$ 


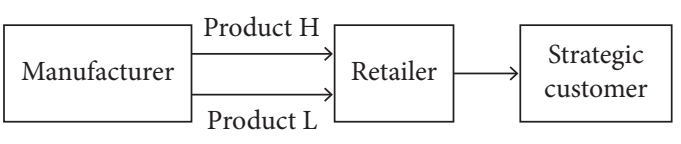

FIGURE 1: Single retail channel model.

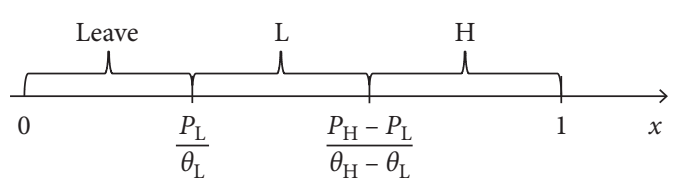

Figure 2: The decision of strategic customers.

$1-\left(P_{H}-P_{L}\right) /\left(\theta_{H}-\theta_{L}\right)$, while the number that chooses to purchase the lower performance products is $\mathrm{Q}^{L}=\int_{\left(P_{L} / \theta_{L}\right)}^{\left(\left(P_{H}-P_{L}\right) /\left(\theta_{H}-\theta_{L}\right)\right)} \mathrm{d} x=\left(P_{H}-P_{L}\right) /\left(\theta_{H}-\theta_{L}\right)-\left(P_{L} / \theta_{L}\right)$, and the number that does not buy any products is $Q_{0}=\left(P_{L} / \theta_{L}\right)$.

Lemma 2. When WTP is close to 1 , the best choice for strategic customers is to buy the higher performance products. When WTP nears zero, strategic customers will leave the market.

3.1.1. Decentralized Decision. The production costs of the higher performance products are $\overline{C^{H}}$ and the lower performance products are $\overline{C^{L}}$. The wholesale prices of these two products are represented by $W^{H}$ and $W^{L}$, respectively. Suppose the manufacturer is the leader and the retailer is the follower, and the two sides follow the Stackelberg game. According to the choices of strategic customers, the profit function of the retailer is

$$
\begin{aligned}
\Pi_{R}= & Q^{H}\left(P_{H}-W^{H}\right)+Q^{L}\left(P_{L}-W^{L}\right) \\
= & \left(1-\frac{P_{H}-P_{L}}{\theta_{H}-\theta_{L}}\right)\left(P_{H}-W^{H}\right) \\
& +\left(\frac{P_{H}-P_{L}}{\theta_{H}-\theta_{L}}-\frac{P_{L}}{\theta_{L}}\right)\left(P_{L}-W^{L}\right) .
\end{aligned}
$$

The profit function of the manufacturer is

$$
\begin{aligned}
\Pi_{M}= & Q^{H}\left(W^{H}-\overline{C^{H}}\right)+Q^{L}\left(W^{L}-\overline{C^{L}}\right) \\
= & \left(1-\frac{P_{H}-P_{L}}{\theta_{H}-\theta_{L}}\right)\left(W^{H}-\overline{C^{H}}\right) \\
& +\left(\frac{P_{H}-P_{L}}{\theta_{H}-\theta_{L}}-\frac{P_{L}}{\theta_{L}}\right)\left(W^{L}-\overline{C^{L}}\right) .
\end{aligned}
$$

Proposition 1. The manufacturer sells higher performance products $H$ and lower performance products $L$ via the single retail channel, and the optimal prices are $W^{H^{*}}=\left(\overline{C^{H}}+\theta_{H}\right) / 2$, $W^{L^{*}}=\left(\overline{C^{L}}+\theta_{L}\right) / 2, P_{H^{*}}=\left(\overline{C^{H}}+3 \theta_{H}\right) / 4$, and $P_{L^{*}}=\left(\overline{C^{L}}+\right.$ $\left.3 \theta_{L}\right) / 4$. The retailer profit is $\Pi_{R \rightarrow D D^{*}}=\left(\left(\theta_{H}-\theta_{L}-\overline{C^{H}}+\overline{C^{L}}\right)\right.$ $\left.\left(\theta_{H}-\overline{C^{H}}\right)\right) /\left(16\left(\theta_{H}-\theta_{L}\right)\right)+\left(\left(\theta_{L} \overline{C^{H}}-\theta_{H} \overline{C^{L}}\right)\left(\theta_{L}-\overline{C^{L}}\right)\right) /$ $\left(16 \theta_{L}\left(\theta_{H}-\theta_{L}\right)\right)$, and the manufacturer profit is $\Pi_{M \longrightarrow D D^{*}}=$
$\left(\left(\theta_{H}-\theta_{L}-\overline{C^{H}}+\overline{C^{L}}\right)\left(\theta_{H}-\overline{C^{H}}\right)\right) /\left(8\left(\theta_{H}-\theta_{L}\right)\right)+\left(\left(\theta_{L} \overline{C^{H}}-\right.\right.$ $\left.\left.\theta_{H} \overline{C^{L}}\right)\left(\theta_{L}-\overline{C^{L}}\right)\right) /\left(8 \theta_{L}\left(\theta_{H}-\theta_{L}\right)\right)=2 \Pi_{R \longrightarrow D D^{*}}$.

Substitute the optimal prices into the expression of the strategic customer number, and we can get $Q^{H}=$ $(1 / 4)-\left(\overline{C^{H}}-\overline{C^{L}}\right) / 4\left(\theta_{H}-\theta_{L}\right), \quad Q^{L}=\left(\theta_{L} \overline{C^{H}}-\theta_{H} \overline{C^{L}}\right) /\left(4 \theta_{L}\right.$ $\left.\left(\theta_{H}-\theta_{L}\right)\right)$, and the number of strategic customers who do not buy any products is $Q_{0}=(3 / 4)+\left(\overline{C^{L}} / 4 \theta_{L}\right)$.

3.1.2. Centralized Decision. The profit function of the supply chain is $\Pi_{Z}=Q^{H}\left(P_{H}-\overline{C^{H}}\right)+Q^{L}\left(P_{L}-\overline{C^{L}}\right)=\left(1-\left(P_{H}-\right.\right.$ $\left.\left.P_{L}\right) /\left(\theta_{H}-\theta_{L}\right)\right)\left(P_{H}-\overline{C^{H}}\right)+\left(\left(P_{H}-P_{L}\right) /\left(\theta_{H}-\theta_{L}\right)-\left(P_{L} /\right.\right.$ $\left.\left.\theta_{L}\right)\right)\left(P_{L}-\overline{C^{L}}\right)$.

Proposition 2. If the single retail channel supply chain is centralized, the optimal price of higher performance products is $P_{Z H^{*}}=\left(\overline{C^{H}}+\theta_{H}\right) / 2$, and the optimal price of lower performance products is $P_{Z L^{*}}=\overline{C^{L}}+\theta_{L} / 2$. The maximum profit of the supply chain is $\Pi_{Z \longrightarrow C D^{*}}=\left(\theta_{L}{\overline{C^{H}}}^{2}+\theta_{H}{\overline{C^{L}}}^{2}-2 \theta_{L} \overline{C^{H} C^{L}}-\right.$ $\left.2 \theta_{L}\left(\theta_{H}-\theta_{L}\right) \overline{C^{H}}+\theta_{H} \theta_{L}\left(\theta_{H}-\theta_{L}\right)\right) /\left(4 \theta_{L}\left(\theta_{H}-\theta_{L}\right)\right)$.

Put the optimal prices into the expression of the strategic customer number, and we can get $Q^{H}=(1 / 2)-\left(\overline{C^{H}}-\overline{C^{L}} /\right.$ $\left.2\left(\theta_{H}-\theta_{L}\right)\right), \quad Q^{L}=\left(\left(\overline{C^{H}}-\overline{C^{L}}\right) /\left(2\left(\theta_{H}-\theta_{L}\right)\right)\right)-\left(C^{L} / 2 \theta_{L}\right)$, and the number of strategic customers who do not buy any products is $Q_{0}=(1 / 2)+\left(C^{L} / 2 \theta_{L}\right)$.

3.2. Sell Product $H$ in Retail Channel and Product $L$ in Electronic Channel. In dual-channel supply-chain model I, the manufacturer sells products $H$ via the retail channel and sells products $L$ in the electronic channel. The sales process is shown in Figure 3.

The price of the retail channel is represented by $P_{S}$ and of the electronic channel is represented by $P_{N}$. The prices meet the criteria $P_{S}>P_{N}$. The preference degree of strategic customers about the electronic channel is denoted by $\mu$, and $0<\mu<1$. The utility function is $U_{S}=\theta_{H} x-P_{S}$ for buying the higher performance products via the retail channel and $U_{N}=\mu \theta_{L} x-P_{N}$ for buying the lower performance products via the electronic channel. The selection function of strategic customers is $V=$ $\max \left\{U_{S}, U_{N}, 0\right\}=\max \left\{\theta_{H} x-P_{S}, \mu \theta_{L} x-P_{N}, 0\right\}$, and then we can get the following expression by comparative analysis:

$$
V= \begin{cases}\theta_{H} x-P_{S}, & x \geq \frac{P_{S}-P_{N}}{\theta_{H}-\mu \theta_{L}}, x \geq \frac{P_{S}}{\theta_{H}}, \\ \mu \theta_{L} x-P_{N}, & x \leq \frac{P_{S}-P_{N}}{\theta_{H}-\mu \theta_{L}}, x \geq \frac{P_{N}}{\mu \theta_{L}}, \\ 0, & x \leq \frac{P_{S}}{\theta_{H}}, x \leq \frac{P_{N}}{\mu \theta_{L}} .\end{cases}
$$

When the parameters meet the condition $\left(P_{N} / \mu \theta_{L}\right) \leq$ $\left(P_{S} / \theta_{H}\right)$, i.e., $\left(\left(P_{S}-P_{N}\right) /\left(\theta_{H}-\mu \theta_{L}\right)\right) \geq\left(P_{S} / \theta_{H}\right) \geq\left(P_{N} / \mu \theta_{L}\right)$, the expression (6) can be derived as follows: 


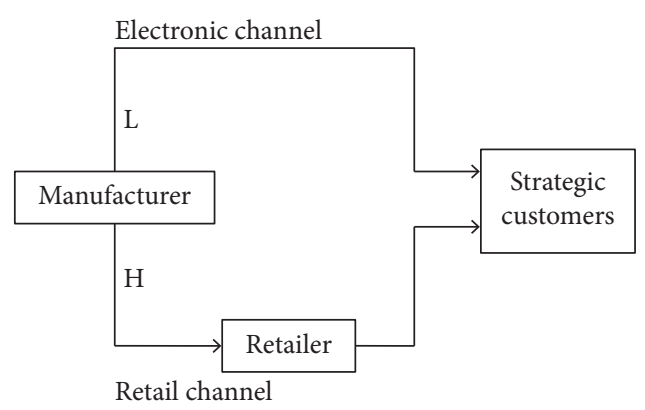

Figure 3: The dual-channel supply-chain model I.

$$
V= \begin{cases}\theta_{H} x-P_{S}, & x \geq \frac{P_{S}-P_{N}}{\theta_{H}-\mu \theta_{L}}, \\ \mu \theta_{L} x-P_{N}, & \frac{P_{N}}{\mu \theta_{L}} \leq x \leq \frac{P_{S}-P_{N}}{\theta_{H}-\mu \theta_{L}}, \\ 0, & x \leq \frac{P_{N}}{\mu \theta_{L}} .\end{cases}
$$

When the parameters meet the condition $\left(P_{N} / \mu \theta_{L}\right) \geq$ $\left(P_{S} / \theta_{H}\right)$, i.e., $\left(\left(P_{S}-P_{N}\right) /\left(\theta_{H}-\mu \theta_{L}\right)\right) \leq\left(P_{S} / \theta_{H}\right) \leq\left(P_{N} / \mu \theta_{L}\right)$, the expression (6) is changed into (8). The strategic customers do not buy products via the electronic channel:

$$
V= \begin{cases}\theta_{H} x-P_{S}, & x \geq \frac{P_{S}}{\theta_{H}}, \\ 0, & x \leq \frac{P_{S}}{\theta_{H}} .\end{cases}
$$

Lemma 3. If the strategic customers can buy the lower performance products via the electronic channel, it needs to meet the prerequisite: $0 \leq\left(P_{N} / \mu \theta_{L}\right) \leq\left(P_{S} / \theta_{H}\right) \leq\left(\left(P_{S}-P_{N}\right) /\right.$ $\left.\left(\theta_{H}-\mu \theta_{L}\right)\right) \leq 1$.

The selections of strategic customers under expression (7) are discussed, and the details are illustrated in Figure 4.

The number of strategic customers that choose to buy the higher performance products via the retail channel is $Q_{S}^{H}=\int_{\left(\left(P_{S}-P_{N}\right) /\left(\theta_{H}-\mu \theta_{L}\right)\right)}^{1} \mathrm{~d} x=1-\left(P_{S}-P_{N}\right) /\left(\theta_{H}-\mu \theta_{L}\right)$, while the number that choose to purchase the lower performance products via the electronic channel is $Q_{N}^{L}=$ $\int_{\left(P_{N} / \mu \theta_{L}\right)}^{\left(\left(P_{S}-P_{N}\right) /\left(\theta_{H}-\mu \theta_{L}\right)\right)} \mathrm{d} x=\left(\left(P_{S}-P_{N}\right) / \theta_{H}-\mu \theta_{L}\right)-\left(P_{N} / \mu \theta_{L}\right)$, and the number that does not buy any products is $Q_{0}=\left(P_{N} / \mu \theta_{L}\right)$.

Lemma 4. When WTP is close to 1 , the best choice for strategic customers is to buy the higher performance products in the retail channel. When WTP nears zero, strategic customers do not buy any products.

3.2.1. Decentralized Decision. According to the choices of strategic customers, the profit function of the retailer is

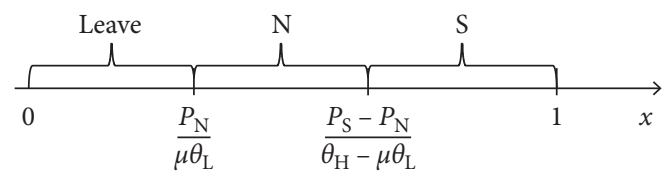

Figure 4: The decision of strategic customers.

$$
\Pi_{R}^{H L}=Q_{S}^{H}\left(P_{S}-W^{H}\right)=\left(1-\frac{P_{S}-P_{N}}{\theta_{H}-\mu \theta_{L}}\right)\left(P_{S}-W^{H}\right) .
$$

The profit function of the manufacturer is

$$
\begin{aligned}
\Pi_{M}^{H L}= & Q_{S}^{H}\left(W^{H}-\overline{C^{H}}\right)+Q_{N}^{L}\left(P_{N}-\overline{C^{L}}\right) \\
= & \left(1-\frac{P_{S}-P_{N}}{\theta_{H}-\mu \theta_{L}}\right)\left(W^{H}-\overline{C^{H}}\right) \\
& +\left(\frac{P_{S}-P_{N}}{\theta_{H}-\mu \theta_{L}}-\frac{P_{N}}{\mu \theta_{L}}\right)\left(P_{N}-\overline{C^{L}}\right) .
\end{aligned}
$$

Proposition 3. The manufacturer sells higher performance product $H$ in the retail channel and lower performance product $L$ via the electronic channel, and the optimal prices is $W^{H^{*}}=\left(\overline{C^{H}}+\theta_{H}\right) / 2, \quad P_{N}^{H L^{*}}=\left(\overline{C^{L}}+\mu \theta_{L}\right) / 2$, and $P_{S}^{H L^{*}}=$ $\left(\overline{C^{H}}+\overline{C^{L}}+3 \theta_{H}-\mu \theta_{L}\right) / 4$. The retailer profit is $\Pi_{R \rightarrow D D}^{H L^{*}}=$ $\left(\theta_{H}-\mu \theta_{L}-\overline{C^{H}}+\overline{C^{L}}\right)^{2} /\left(16\left(\theta_{H}-\mu \theta_{L}\right)\right)$, and the manufacturer profit is $\Pi_{M \longrightarrow D D}^{H L^{*}}=\left(\bar{C}^{H^{2}} /\left(8\left(\theta_{H}-\mu \theta_{L}\right)\right)\right)+\left(\left(\left(2 \theta_{H}-\right.\right.\right.$ $\left.\left.\left.\mu \theta_{L}\right){\overline{C^{L}}}^{2}\right) /\left(2 \mu \theta_{L}\left(\theta_{H}-\mu \theta_{L}\right)\right)\right)-\left(\overline{C^{H} C^{L}}\right) /\left(4\left(\theta_{H}-\mu \theta_{L}\right)\right)-\left(\overline{C^{H}}\right.$ $\left.+\overline{C^{L}}\right) / 4+\left(\theta_{H}+\mu \theta_{L}\right) / 8$.

Then substitute the optimal prices into the expression of the strategic customer number, and we can get $Q_{S}^{H}=$ $(1 / 4)-\left(\left(\overline{C^{H}}-\overline{C^{L}}\right) /\left(4\left(\theta_{H}-\mu \theta_{L}\right)\right)\right), Q_{N}^{L}=(1 / 4)+\left(\mu \theta_{L} \overline{C^{H}}-\right.$ $\left.\left(2 \theta_{H}-\mu \theta_{L}\right) \overline{C^{L}}\right) /\left(4 \mu \theta_{L}\left(\theta_{H}-\mu \theta_{L}\right)\right)$, and the number of strategic customers who do not buy any products $Q_{0}=(1 / 2)+\left(\overline{C^{L}} /\left(2 \mu \theta_{L}\right)\right)$.

3.2.2. Centralized Decision. The profit function of the supply chain is $\Pi_{Z}^{H L}=Q_{S}^{H}\left(P_{S}-\overline{C^{H}}\right)+Q_{N}^{L}\left(P_{N}-\overline{C^{L}}\right)=\left(1-\left(\left(P_{S}-\right.\right.\right.$ $\left.\left.\left.P_{N}\right) /\left(\theta_{H}-\mu \theta_{L}\right)\right)\right)\left(P_{S}-\overline{C^{H}}\right)+\left(\left(\left(P_{S}-P_{N}\right) /\left(\theta_{H}-\mu \theta_{L}\right)\right)-\right.$ $\left.\left(P_{N} / \mu \theta_{L}\right)\right)\left(P_{N}-\overline{C^{L}}\right)$.

Proposition 4. If the dual-channel supply chain is centralized, the optimal price of higher performance products in the retail channel is $P_{Z S}^{H L^{*}}=\left(\overline{C^{H}}+\theta_{H}\right) / 2$, and the optimal price of lower performance products in electronic channel is $P_{Z N}^{H L^{*}}=$ $\left(\overline{C^{L}}+\mu \theta_{L}\right) / 2$. The maximum profit of the supply chain

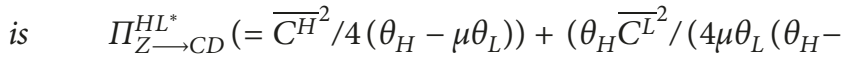
$\left.\left.\left.\mu \theta_{L}\right)\right)\right)-\left(\left(\overline{C^{H} C^{L}}\right) /\left(2\left(\theta_{H}-\mu \theta_{L}\right)\right)\right)-\left(\overline{C^{H}} / 2\right)+\left(\theta_{H} / 4\right)$.

Put the optimal prices into the expression of strategic customer number, and we can get $Q_{S}^{H}=(1 / 2)-\left(\left(\overline{C^{H}}-\right.\right.$ $\left.\left.\overline{C^{L}}\right) /\left(2\left(\theta_{H}-\mu \theta_{L}\right)\right)\right), \quad Q_{N}^{L}=\left(\left(\overline{C^{H}}-\overline{C^{L}}\right) /\left(2\left(\theta_{H}-\mu \theta_{L}\right)\right)\right)-$ 
$\left(\overline{C^{L}} / 2 \mu \theta_{L}\right)$, and the number of strategic customers who do not buy any products is $Q_{0}=(1 / 2)+\left(\overline{C^{L}} / 2 \mu \theta_{L}\right)$.

3.3. Sell Product L in Retail Channel and Product $H$ in Electronic Channel. In the dual-channel supply-chain model II, the manufacturer sells products $L$ via the retail channel and sells products $H$ in the electronic channel. The sales process is shown in Figure 5.

The utility function for buying the higher performance products via the retail channel is $U_{S}=\theta_{L} x-P_{S}$ and for buying the lower performance products via the electronic channel is $U_{N}=\mu \theta_{H} x-P_{N}$. Suppose sale prices meet the requirement $P_{N}>P_{S}$. The selection function of strategic customers is $V=$ $\max \left\{U_{S}, U_{N}, 0\right\}=\max \left\{\theta_{L} x-P_{S}, \mu \theta_{H} x-P_{N}, 0\right\}$.

When the parameters meet the condition $\left(P_{S} / \theta_{L}\right) \leq\left(P_{N} /\right.$ $\left.\mu \theta_{H}\right)$, i.e., $\quad\left(\left(P_{N}-P_{S}\right) /\left(\mu \theta_{H}-\theta_{L}\right)\right) \geq\left(P_{N} / \mu \theta_{H}\right) \geq\left(P_{S} / \theta_{L}\right)$, the selection function can be derived as follows:

$$
V= \begin{cases}\theta_{L} x-P_{S}, & \frac{P_{S}}{\theta_{L}} \leq x \leq \frac{P_{N}-P_{S}}{\mu \theta_{H}-\theta_{L}}, \\ \mu \theta_{H} x-P_{N}, & x \geq \frac{P_{N}-P_{S}}{\mu \theta_{H}-\theta_{L}}, \\ 0, & x \leq \frac{P_{S}}{\theta_{L}}\end{cases}
$$

When the parameters meet the condition $\left(P_{S} / \theta_{L}\right) \geq$ $\left(P_{N} / \mu \theta_{H}\right)$, i.e., $\left(\left(P_{N}-P_{S}\right) /\left(\mu \theta_{H}-\theta_{L}\right)\right) \leq\left(P_{N} / \mu \theta_{H}\right) \leq\left(P_{S} /\right.$ $\left.\theta_{L}\right)$, the selection function is changed into (12). The strategic customers do not buy lower performance products in the retail channel:

$$
V=\left\{\begin{array}{cc}
\mu \theta_{H} x-P_{N}, & x \geq \frac{P_{N}}{\mu \theta_{H}}, \\
0, & x \leq \frac{P_{N}}{\mu \theta_{H}} .
\end{array}\right.
$$

Lemma 5. If the strategic customers can purchase products from the retail channel and electronic channel, it needs to meet the prerequisite: $0 \leq\left(P_{S} / \theta_{L}\right) \leq\left(P_{N} / \mu \theta_{H}\right) \leq\left(\left(P_{N}-P_{S}\right) /\right.$ $\left.\left(\mu \theta_{H}-\theta_{L}\right)\right) \leq 1$.

The selections of strategic customers under expression (11) are discussed, and the details are illustrated in Figure 6.

The number of strategic customers that chooses to buy the higher performance products via the electronic channel is $Q_{N}^{H}=\int_{\left(\left(P_{N}-P_{S}\right) /\left(\mu \theta_{H}-\theta_{L}\right)\right)}^{1} \mathrm{~d} x=1-\left(\left(P_{N}-P_{S}\right) /\left(\mu \theta_{H}-\theta_{L}\right)\right)$, while the number that chooses to purchase the lower performance products via the retail channel is $Q_{S}^{L}=$ $\int_{\left(P_{S} / \theta_{L}\right)}^{\left(P_{N}-P_{S}\right) /\left(\mu \theta_{H}-\theta_{L}\right)} d x=\left(\left(P_{N}-P_{S}\right) /\left(\mu \theta_{H}-\theta_{L}\right)\right)-\left(P_{S} / \theta_{L}\right)$, and the number that does not buy any products is $Q_{0}=\left(P_{S} / \theta_{L}\right)$.

Lemma 6. When WTP is close to 1, the best choice for strategic customers is to buy the higher performance products

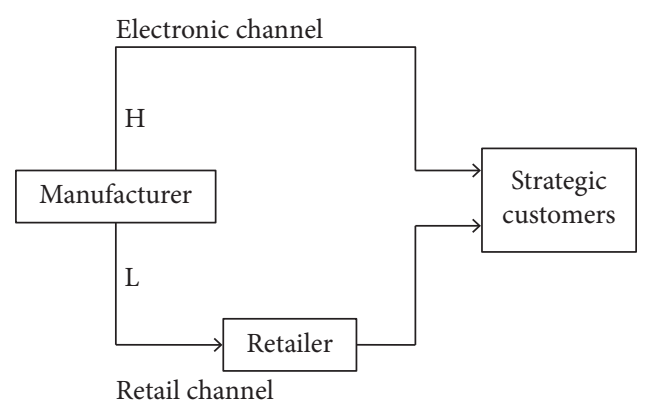

FIgURE 5: The dual-channel supply-chain model II.

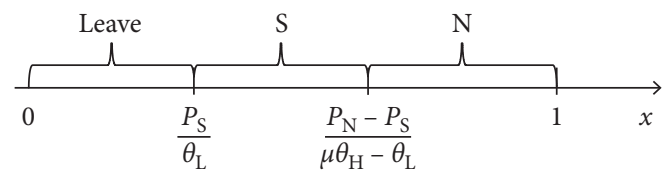

FIgURE 6: The decision of strategic customers.

in the electronic channel. When WTP nears zero, the strategic customers do not buy any products.

3.3.1. Decentralized Decision. According to the choices of strategic customers, the profit function of the retailer is

$$
\Pi_{R}^{L H}=Q_{S}^{L}\left(P_{S}-W^{L}\right)=\left(\frac{P_{N}-P_{S}}{\mu \theta_{H}-\theta_{L}}-\frac{P_{S}}{\theta_{L}}\right)\left(P_{S}-W^{L}\right) .
$$

The profit function of the manufacturer is

$$
\begin{aligned}
\Pi_{M}^{L H}= & Q_{S}^{L}\left(W^{L}-\overline{C^{L}}\right)+Q_{N}^{H}\left(P_{N}-\overline{C^{H}}\right) \\
= & \left(\frac{P_{N}-P_{S}}{\mu \theta_{H}-\theta_{L}}-\frac{P_{S}}{\theta_{L}}\right)\left(W^{L}-\overline{C^{L}}\right) \\
& +\left(1-\frac{P_{N}-P_{S}}{\mu \theta_{H}-\theta_{L}}\right)\left(P_{N}-\overline{C^{H}}\right) .
\end{aligned}
$$

Proposition 5. The manufacturer sells lower performance product $L$ in the retail channel and higher performance product $H$ via electronic channel, and the optimal prices are $W^{L^{*}}=$ $\left(\overline{C^{L}}+\theta_{L}\right) / 2, \quad P_{N}^{L H^{*}}=\left(\overline{C^{H}}+\mu \theta_{H}\right) / 2$, and $P_{S}^{L H^{*}}=\left(\theta_{L} \overline{C^{H}}+\right.$ $\left.\mu \theta_{H} \overline{C^{L}}+2 \mu \theta_{H} \theta_{L}\right) /\left(4 \mu \theta_{H}\right)$. The retailer profit is $\Pi_{R \rightarrow D D}^{L H}=$ $\left(\theta_{L} \overline{C^{H}}-\mu \theta_{H} \overline{C^{L}}\right)^{2} /\left(16 \mu \theta_{H} \theta_{L}\left(\mu \theta_{H}-\theta_{L}\right)\right)$, and the maximum profit of the manufacturer is $\Pi_{M \longrightarrow D D}^{L H}=\left(\left(\left(2 \mu \theta_{H}-\theta_{L}\right)\right.\right.$ \left.\left.${\overline{C^{H}}}^{2}\right) /\left(8 \mu \theta_{H}\left(\mu \theta_{H}-\theta_{L}\right)\right)\right)+\left(\left(\mu \theta_{H}{\overline{C^{L}}}^{2}\right) /\left(8 \theta_{L}\left(\mu \theta_{H}-\theta_{L}\right)\right)\right)-$ $\left(\left(\overline{C^{H} C^{L}}\right) / 4\left(\mu \theta_{H}-\theta_{L}\right)\right)-\left(\overline{C^{H}} / 2\right)+\left(\mu \theta_{H} / 4\right)$.

Then, substitute the optimal prices into the expression of the strategic customer number, and we can get $Q_{N}^{H}=$ $1 / 2-\left(\left(2 \mu \theta_{H}-\theta_{L}\right) \overline{C^{H}}-\mu \theta_{H} \overline{C^{L}}\right) /\left(4 \mu \theta_{H}\left(\mu \theta_{H}-\theta_{L}\right)\right), \quad Q_{S}^{L}=$ $\left(\theta_{L} \overline{C^{H}}-\mu \theta_{H} \overline{C^{L}}\right) /\left(4 \theta_{L}\left(\mu \theta_{H}-\theta_{L}\right)\right)$, and the number of strategic customers who do not buy any products is $Q_{0}=(1 / 2)+\left(\left(\theta_{L} \overline{C^{H}}+\mu \theta_{H} \overline{C^{L}}\right) /\left(4 \mu \theta_{H} \theta_{L}\right)\right)$. 
3.3.2. Centralized Decision. The profit function of the supply chain is $\Pi_{Z}^{L H}=Q_{S}^{L}\left(P_{S}-\overline{C^{L}}\right)+Q_{N}^{H}\left(P_{N}-\overline{C^{H}}\right)=\left(\left(P_{N}-P_{S} /\right.\right.$ $\left.\left.\mu \theta_{H}-\theta_{L}\right)-\left(P_{S} / \theta_{L}\right)\right)\left(P_{S}-\overline{C^{L}}\right)+\left(1-\left(\left(P_{N}-P_{S}\right) /\left(\mu \theta_{H^{-}}\right.\right.\right.$ $\left.\left.\theta_{L}\right)\right)\left(P_{N}-\overline{C^{H}}\right)$.

Proposition 6. If the dual-channel supply chain is centralized, the optimal price of lower performance products in the retail channel is $P_{Z S}^{L H^{*}}=\left(\overline{C^{L}}+\theta_{L} / 2\right)$, and the optimal price of higher performance products in the electronic channel is $P_{Z N}^{L H^{*}}=\left(\overline{C^{H}}+\mu \theta_{H}\right) / 2$. The maximum profit of the supply chain is $\Pi_{Z \longrightarrow C D}^{H L^{*}}=\left({\overline{C^{H}}}^{2} / 4\left(\mu \theta_{H}-\theta_{L}\right)\right)+\left(\left(\mu \theta_{H} \bar{C}^{2}\right) /\left(4 \theta_{L}\right.\right.$ $\left.\left.\left(\mu \theta_{H}-\theta_{L}\right)\right)\right)-\left(\left(\overline{C^{H} C^{L}}\right) / 2\left(\mu \theta_{H}-\theta_{L}\right)\right)-\left(\overline{C^{H}} / 2\right)+\mu \theta_{H} / 4$.

Put the optimal prices into the expression of the strategic customer number, and we can get $Q_{N}^{H}=(1 / 2)-\left(\left(\overline{C^{H}}-\overline{C^{L}}\right) / 2\right.$ $\left.\left(\mu \theta_{H}-\theta_{L}\right)\right), \quad Q_{S}^{L}=\left(\left(\overline{C^{H}}-\overline{C^{L}}\right) /\left(2\left(\mu \theta_{H}-\theta_{L}\right)\right)\right)-\left(\overline{C^{L}} / 2 \theta_{L}\right)$, and the number of strategic customers who do not buy any products is $Q_{0}=(1 / 2)+\left(\overline{C^{L}} / 2 \theta_{L}\right)$.

Based on the above analysis, this paper compares the influence of parameters $\theta_{H}$ and $\theta_{L}$ on optimal pricing strategies and customer numbers in three different models. The change trend is shown in Table 1.

\section{Numerical Analysis}

\subsection{The Influence of Parameters on the Single Retail Channel Model}

4.1.1. The Influence of Parameter $\theta_{H}$ on Optimal Decisions. We set $\overline{C^{H}}=0.4, \overline{C^{L}}=0.3$, and $\theta_{L}=0.7$, and then the value range of the parameter $\theta_{H}$ is $\left[\theta_{L}, 1\right]$. In the decentralized dualchannel supply chain, $W^{H^{*}}=\left(0.4+\theta_{H}\right) / 2, \quad W^{L^{*}}=0.5$, $P_{H}^{*}=\left(0.4+3 \theta_{H} / 4\right)$, and $P_{L}^{*}=0.6$, the profit function of the retailer is $\Pi_{R \longrightarrow D D}^{*}=\left(\theta_{H}^{2}-1.35 \theta_{H}+0.46\right) /\left(14\left(\theta_{H}-0.7\right)\right)$, and the profit function of the manufacturer is $\Pi_{M \rightarrow D D}^{*}=$ $\left(\theta_{H}^{2}-1.35 \theta_{H}+0.46\right) /\left(7\left(\theta_{H}-0.7\right)\right)$. In centralized dualchannel supply chains, $P_{Z H}^{*}=0.4+\theta_{H} / 2$ and $P_{Z L}^{*}=0.5$, the supply-chain profit is $\Pi_{Z \longrightarrow C D}^{*}=\left(0.7 \theta_{H}^{2}-0.96 \theta_{H}+0.336\right) /$ $\left(2.8\left(\theta_{H}-0.7\right)\right)$. The influence of parameter $\theta_{H}$ on optimal prices and the optimal profits is shown by Figure 7 .

In this type, both the higher performance products and the lower performances products are selected by strategic customers. According to Lemma 1, we can deduce that $\left(P_{L} / \theta_{L}\right) \leq\left(P_{H} / \theta_{H}\right)$ and $\left(P_{H}-P_{L}\right) /\left(\theta_{H}-\theta_{L}\right) \leq 1$ and then get the range $0.8 \leq \theta_{H} \leq 0.93$. In this interval, the optimal prices meet the following relationship: $P_{H}^{*}>W^{H *}>P_{L}^{*}>W^{L *}$. The wholesale price of higher performance products is more than the sale price of lower performance products. With the parameter $\theta_{H}$ increasing, these profit functions will increase, the gap will widen between manufacturer profit and retailer profit, and the difference between the total profit of centralized decision and of decentralized decision $\Delta \Pi_{Z}^{H L}$ has no obvious change.

4.1.2. The Influence of Parameter $\theta_{L}$ on Optimal Decisions. Set $\overline{C^{H}}=0.4, \overline{C^{L}}=0.3$, and $\theta_{H}=0.9$, and we can get the value range of $\theta_{L}$ is $\left[0, \theta_{H}\right]$. In the decentralized dual-channel supply chain, $W^{H^{*}}=0.65, W^{L^{*}}=\left(0.3+\theta_{L}\right) / 2, P_{H}^{*}=0.775$, and
$P_{L}^{*}=\left(0.3+3 \theta_{L}\right) / 4$, the maximum profit function of the retailer is $\Pi_{R \longrightarrow D D}^{*}=\left(-0.1 \theta_{L}^{2}+0.01 \theta_{L}+0.081\right) /\left(16 \theta_{L}(0.9-\right.$ $\left.\theta_{L}\right)$ ) and the profit function of the manufacturer is $\Pi_{M \longrightarrow D D}^{*}=\left(-0.1 \theta_{L}^{2}+0.01 \theta_{L}+0.081\right) /\left(8 \theta_{L}\left(0.9-\theta_{L}\right)\right)$. In centralized dual-channel supply chains, $P_{Z H}^{*}=0.65$ and $P_{Z L}^{*}=\left(0.3+\theta_{L} / 2\right)$, the supply-chain profit is $\Pi_{Z \longrightarrow D D}^{*}=$ $\left(-0.1 \theta_{L}^{2}+0.01 \theta_{L}+0.081\right) /\left(4 \theta_{L}\left(0.9-\theta_{L}\right)\right)$. The influence of parameter $\theta_{L}$ on optimal prices and the optimal profits is shown in Figure 8.

According to Lemma 1, we can deduce that $0.675 \leq \theta_{L} \leq 0.8$. In range $[0.675,0.77]$, the optimal prices have following relationship: $P_{H}^{*}>W^{H^{*}}>P_{L}^{*}>W^{L^{*}}$; in range $[0.675,0.8]$, the optimal prices have the following relationship: $P_{H}^{*}>P_{L}^{*}>W^{H^{*}}>W^{L^{*}}$, the sale price of lower performance products exceeds the wholesale price of higher performance products. As parameter $\theta_{L}$ increases, these profit functions are all essentially unchanged, and $\Pi_{Z \longrightarrow D D}^{*}=2 \Pi_{R \longrightarrow D D}^{*}=$ $4 \Pi_{R \longrightarrow D D^{*}}^{*}$

\subsection{The Influence of Parameters on the Dual-Channel Model I}

4.2.1. The Influence of Parameter $\theta_{H}$ on Optimal Decisions. Set $\overline{C^{H}}=0.4, \overline{C^{L}}=0.3, \theta_{L}=0.6$, and $\mu=1$, the range of the parameter $\theta_{H}$ is $\left[\theta_{L}, 1\right]$. When the dual-channel supply chain is decentralized, the optimal prices are $W^{H^{*}}=\left(0.4+\theta_{H}\right) / 2$, $P_{N}^{H L^{*}}=0.45$, and $P_{S}^{H L^{*}}=\left(0.1+3 \theta_{H}\right) / 4$. The profit function of the retailer is $\Pi_{R \rightarrow D D}^{H L^{*}}=\left(\left(\theta_{H}-0.7\right)^{2} / 16\left(\theta_{H}-0.6\right)\right)$, the profit of the manufacturer is $\Pi_{M \longrightarrow D D}^{H L^{*}}=\left(\theta_{H}^{2}-1.1 \theta_{H}+\right.$ $0.31) / 8\left(\theta_{H}-0.6\right)$, and the supply-chain profit is $\Pi_{M \rightarrow D D}^{H L^{*}}=$ $\left(3 \theta_{H}^{2}-3.6 \theta_{H}+1.11\right) /\left(16\left(\theta_{H}-0.6\right)\right)$. In the centralized supply chain, the optimal prices $P_{Z S}^{H L^{*}}=\left(0.4+\theta_{H}\right) / 2$ and $P_{Z N}^{H L^{*}}=0.45$, and the maximum profit of supply chain is

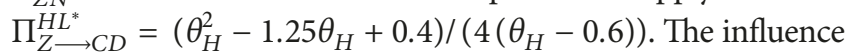
of the parameter $\theta_{H}$ on optimal prices and the optimal profits is shown in Figure 9.

On the basis of Lemma 3, when the strategic customers select to buy products via the electronic channel, it needs to meet the following criteria: $\left(P_{N} / \theta_{L}\right) \leq\left(P_{S} / \theta_{H}\right)$ and $\left(P_{S}-P_{N}\right) /\left(\theta_{H}-\theta_{L}\right) \leq 1$, and we can get the range $\theta_{H} \geq 0.7$. In the interval, the optimal prices have the following relationship: $P_{S}^{H L^{*}}>W^{H^{*}}>P_{N}^{H L^{*}}$. The wholesale price of higher performance products in the retail channel is higher than the sale price of lower performance products in the electronic channel, and the manufacturer profit is more than the retailer profit, and the profit of centralized decision is superior to the profit of decentralized decision. With the parameter $\theta_{H}$ increasing, prices $W^{H^{*}}$ and $P_{S}^{H L^{*}}$ will increase, and $P_{N}^{H L^{*}}$ will be no change; the profit functions will increase, and the difference between the total profit of centralized decision and of decentralized decision $\Delta \Pi_{Z}^{H L}$ will be bigger and bigger.

4.2.2. The Influence of Parameter $\theta_{L}$ on Optimal Decisions. Set $\overline{C^{H}}=0.4, \overline{C^{L}}=0.3, \theta_{H}=0.9$, and $\mu=1$, and the range of the parameter $\theta_{L}$ is $\left[0, \theta_{H}\right]$. In the decentralized supply chain, the prices $W^{H^{*}}=0.65, P_{N}^{H L^{*}}=\left(0.3+\theta_{L}\right) / 2$, and $P_{S}^{H L^{*}}=$ $\left(3.4-\theta_{L}\right) / 4$. The retailer profit is $\Pi_{R \longrightarrow D D}^{H L^{*}}=\left(\left(0.8-\theta_{L}\right)^{2} /\right.$ $\left.16\left(0.9-\theta_{L}\right)\right)$, the manufacturer profit is $\Pi_{M \longrightarrow D D}^{H L^{*}}=\left(-\theta_{L}^{3}+\right.$ 
TABLE 1: The influence of parameters on optimal price strategy and number of customers.

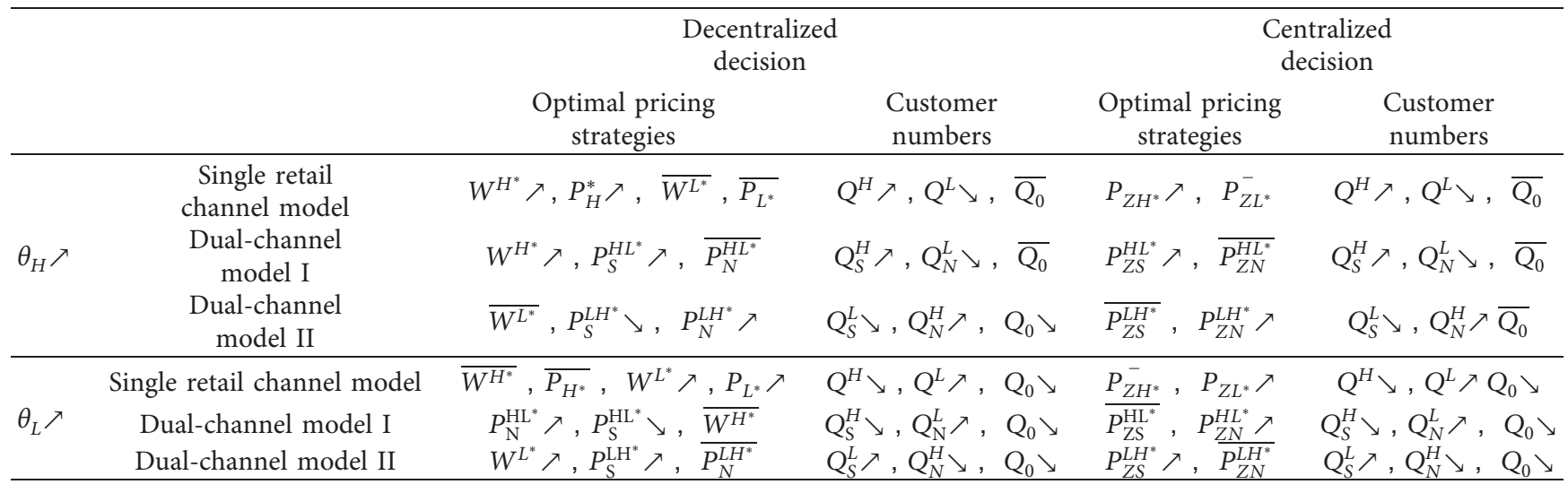

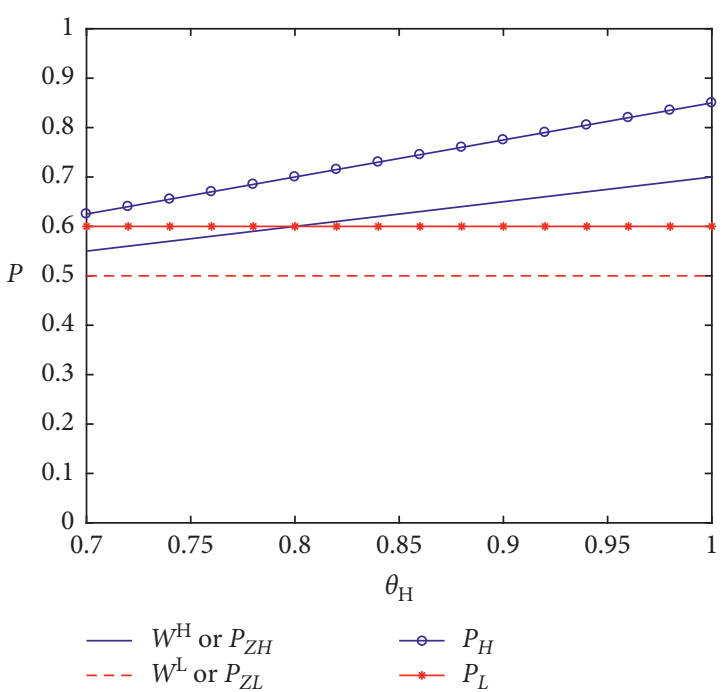

(a)

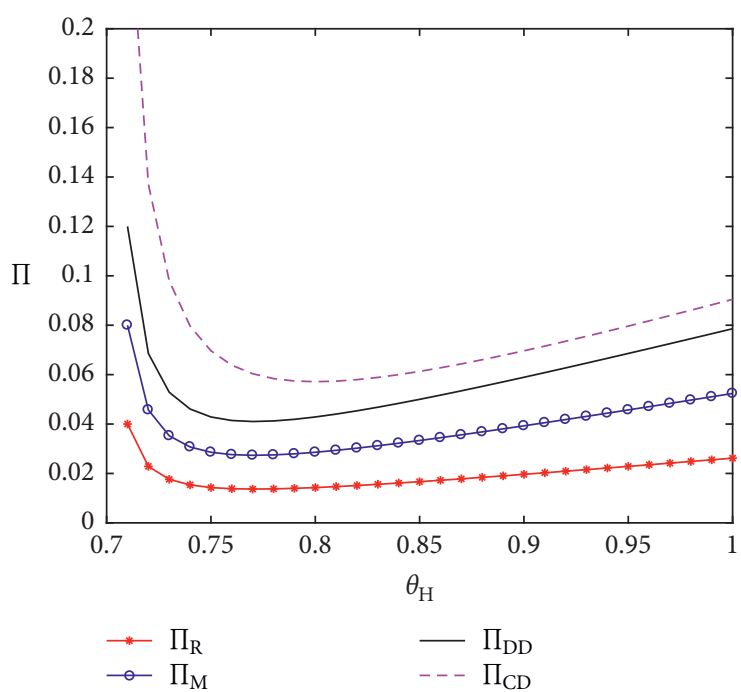

(b)

Figure 7: The influence of parameter $\theta_{H}$ on optimal decisions.

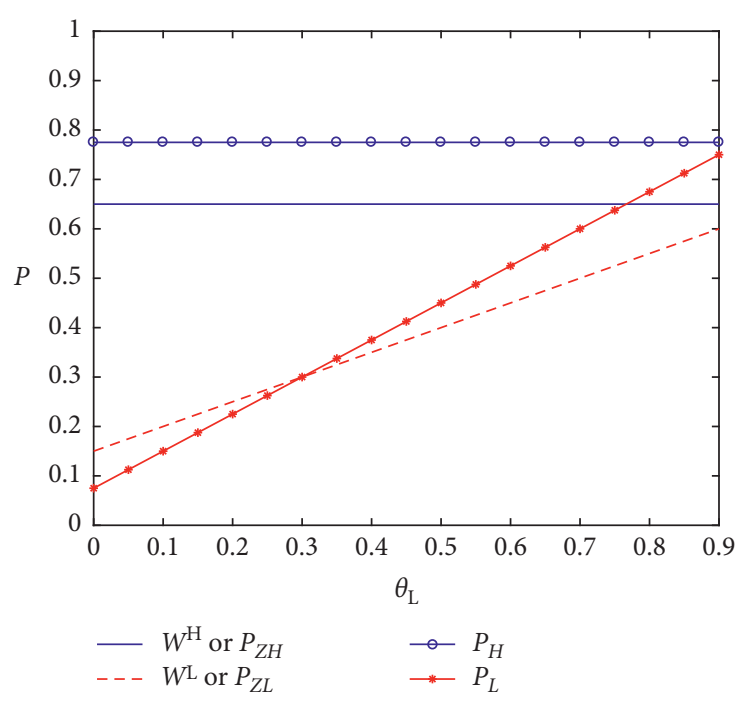

(a)

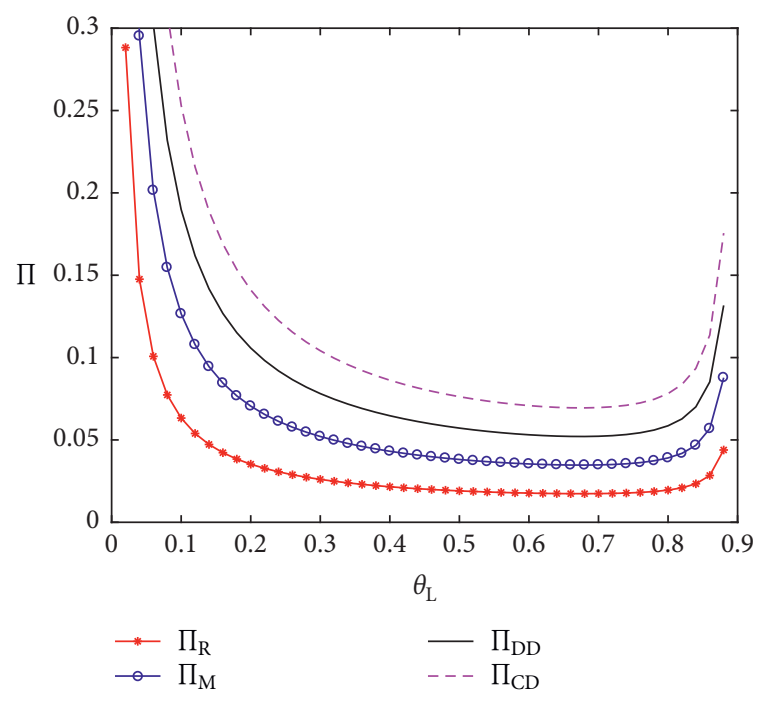

(b)

Figure 8: The influence of parameter $\theta_{L}$ on optimal decisions. 


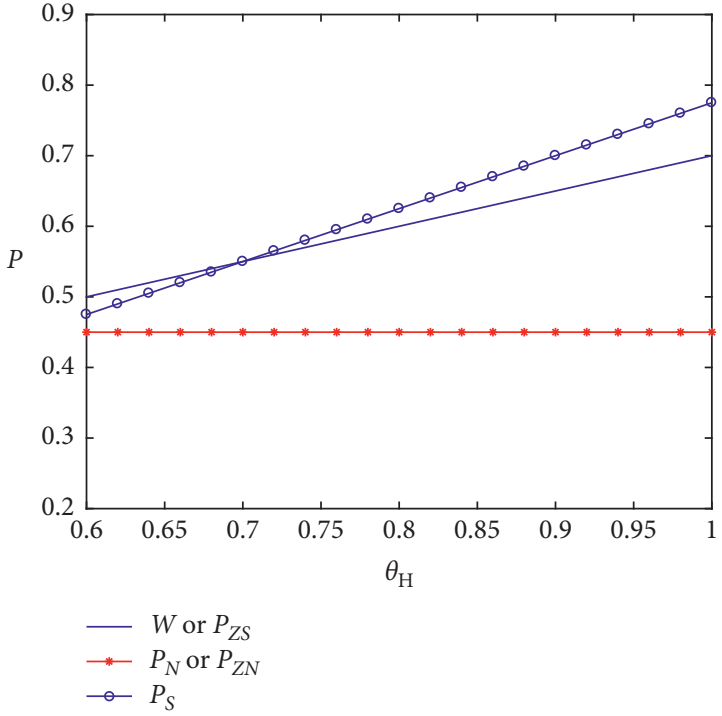

(a)

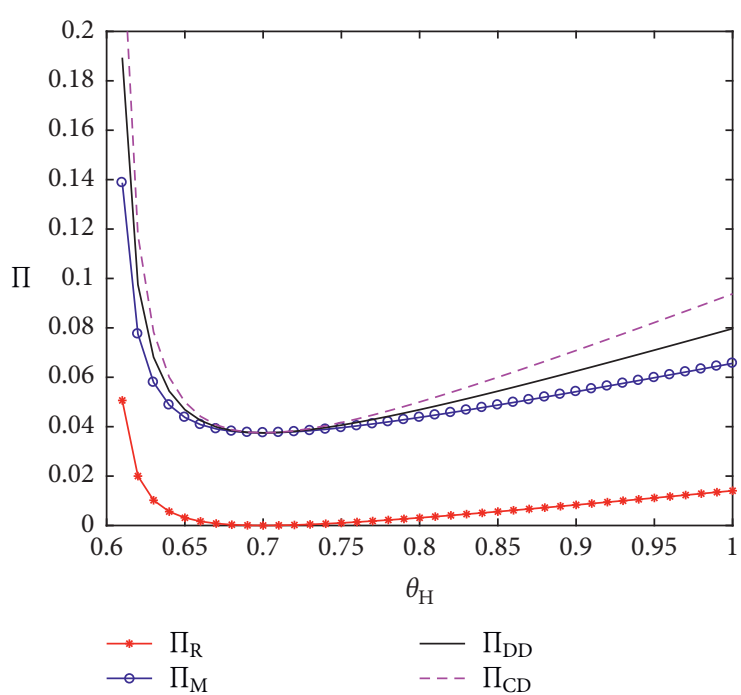

(b)

Figure 9: The influence of parameter $\theta_{H}$ on optimal decisions.

$\left.1.4 \theta_{L}^{2}-0.62 \theta_{L}+0.162\right) /\left(8 \theta_{L}\left(0.9-\theta_{L}\right)\right)$, and the profit of the supply chain is $\Pi_{Z \longrightarrow D D}^{H L^{*}}=\left(-\theta_{L}^{3}+1.2 \theta_{L}^{2}-0.6 \theta_{L}+0.324\right) /$ $\left(16 \theta_{L}\left(0.9-\theta_{L}\right)\right)$. In the centralized supply chain, the optimal prices are $P_{Z S}^{H L^{*}}=0.65$ and $P_{Z N}^{H L^{*}}=\left(0.3+\theta_{L} / 2\right)$, and the profit of the supply chain is $\Pi_{Z L^{*}} \longrightarrow C D=\left(-0.1 \theta_{L}^{2}+0.01 \theta_{L}+0.081\right) /$ $\left(4 \theta_{L}\left(0.9-\theta_{L}\right)\right)$. The influence of the parameter $\theta_{L}$ on optimal prices and the optimal profits is shown in Figure 10.

Similarly, we can deduce that the range of the parameter $\theta_{L}$ is $0.48<\theta_{L}<0.8$, according to Lemma 3. In the interval $[0.48,0.8]$, the optimal prices have the following relationship: $P_{S}^{H L^{*}}>W^{H^{*}}>P_{N}^{H L^{*}}$; the profit of the centralized supply chain is superior to the profit of the decentralized supply chain, and the manufacturer profit is significantly higher than the retailer profit. As the parameter $\theta_{L}$ grows, the sale price of higher performance products in retail channel $P_{S}^{H L^{*}}$ decreases, and the sale price of lower performance products in electronic channel $P_{N}^{H L^{*}}$ increases, but the wholesale price $W^{H^{*}}$ remains the same; the manufacturer profit and the profit of the decentralized supply chain increase, while the retailer profit and the profit of centralized supply chain decrease. And the difference between the total profit of centralized decision and of decentralized decision $\Delta \Pi_{Z}^{H L}$ will be smaller and smaller.

\subsection{The Influence of Parameters on the Dual-Channel Model II}

4.3.1. The Influence of Parameter $\theta_{H}$ on Optimal Decisions. Set $\overline{C^{H}}=0.4, \overline{C^{L}}=0.3, \theta_{L}=0.6$, and $\mu=1$, and the range of parameter $\theta_{H}$ is $\left[\theta_{L}, 1\right]$. In the decentralized supply chain, the optimal prices are $W^{L^{*}}=0.45, P_{N}^{L H^{*}}=\left(0.4+\theta_{H}\right) / 2$, and $P_{S}^{L H^{*}}=\left(\left(0.24+1.5 \theta_{H}\right) / 4 \theta_{H}\right)$, and then the maximum profit of the retailer is $\Pi_{R \longrightarrow D D}^{L H}=\left(0.24-0.3 \theta_{H}\right)^{2} / 9.6 \theta_{H}\left(\theta_{H}-0.6\right)$; meanwhile, the maximum profit of the manufacturer is $\Pi_{M \longrightarrow D D}^{L H}=\left(1.2 \theta_{H}^{3}-1.59 \theta_{H}^{2}+0.624 \theta_{H}-0.0576\right) /\left(4.8 \theta_{H}\right.$ $\left.\left(\theta_{H}-0.6\right)\right)$, and the supply-chain profit is $\Pi_{Z \rightarrow D D}^{H L^{*}}=\left(\theta_{H^{-}}^{3}\right.$ $\left.1.2875 \theta_{H}^{2}+0.46 \theta_{H}-0.024\right) /\left(4 \theta_{H}\left(\theta_{H}-0.6\right)\right)$. In the centralized supply chain, the optimal prices are $P_{Z S}^{L H^{*}}=0.45$ and
$P_{Z N}^{L H^{*}}=\left(0.4+\theta_{H}\right) / 2$, and the supply-chain profit is $\Pi_{Z \longrightarrow C D}^{H L^{*}}=\left(\theta_{H}^{2}-1.25 \theta_{H}+0.4\right) /\left(4\left(\theta_{H}-0.6\right)\right)$. The influence of the parameter $\theta_{H}$ on optimal prices and the optimal profits is shown in Figure 11.

According to Lemma 5, it needs to meet the following prerequisite: $\left(P_{S} / \theta_{L}\right) \leq\left(P_{N} / \theta_{H}\right)$ and $\left(P_{N}-P_{S}\right) /\left(\theta_{H}-\theta_{L}\right) \leq$ 1 , and then we can deduce that the range of the parameter $\theta_{H}$ is $0.67<\theta_{H}<0.8$. In this interval, the optimal prices have the following relationship: $P_{N}^{L H^{*}}>P_{S}^{L H^{*}}>W^{L^{*}}$, the price of higher performance products in the electronic channel is more than the price of lower performance products in the retailer channel, also more than the wholesale price of lower performance products. The manufacturer profit is obviously higher than retailer profit, and the profit of the centralized supply chain is slightly above the profit of the decentralized supply chain. As the parameter $\theta_{H}$ increases, $P_{N}^{L H^{*}}$ increases, but $P_{S}^{L H^{*}}$ decreases, and $W^{L^{*}}$ remains the same; the retailer profit reduces gradually, while the other three profits firstly decrease and then increase and, finally, come together. And the difference between the total profit of centralized decision and of decentralized decision $\Delta \Pi_{Z}^{L H}$ will be smaller and smaller.

4.3.2. The Influence of Parameter $\theta_{L}$ on Optimal Decisions. Set $\overline{C^{H}}=0.4, \overline{C^{L}}=0.3, \theta_{H}=0.9$, and $\mu=1$, and the range of parameter $\theta_{L}$ is $\left[0, \theta_{H}\right]$. When the supply chain is decentralized, the optimal prices are $W^{L^{*}}=\left(0.3+\theta_{L} / 2\right), P_{N}^{L H^{*}}=$ 0.65 , and $P_{S}^{L H^{*}}=\left(2.2 \theta_{L}+0.27\right) / 3.6$, and the retailer profit is $\Pi_{R \longrightarrow D D}^{L H}=\left(0.4 \theta_{L}-0.27\right)^{2} /\left(14.4 \theta_{L}\left(0.9-\theta_{L}\right)\right)$, the manufacturer profit is $\Pi_{M \longrightarrow D D}^{L H}=\left(-0.34 \theta_{L}^{2}+0.234 \theta_{L}+0.0729\right) /$ $\left(7.2 \theta_{L}\left(0.9-\theta_{L}\right)\right)$, and the supply-chain profit is $\Pi_{Z \longrightarrow D D}^{H L^{*}}=$ $\left(-0.52 \theta_{L}^{2}+0.252 \theta_{L}+0.2187\right) /\left(14.4 \theta_{L}\left(0.9-\theta_{L}\right)\right)$. When the supply chain is centralized, the optimal prices are $P_{Z S}^{L H^{*}}=\left(0.3+\theta_{L}\right) / 2$ and $P_{Z N}^{L H^{*}}=0.65$, and the supply-chain profit is $\Pi_{Z \longrightarrow C D}^{H L^{*}}=\left(-0.1 \theta_{L}^{2}+0.01 \theta_{L}+0.081\right) /\left(4 \theta_{L}(0.9-\right.$ $\left.\left.\theta_{L}\right)\right)$. The influence of the parameter $\theta_{L}$ on optimal prices and the optimal profits is shown in Figure 12. 


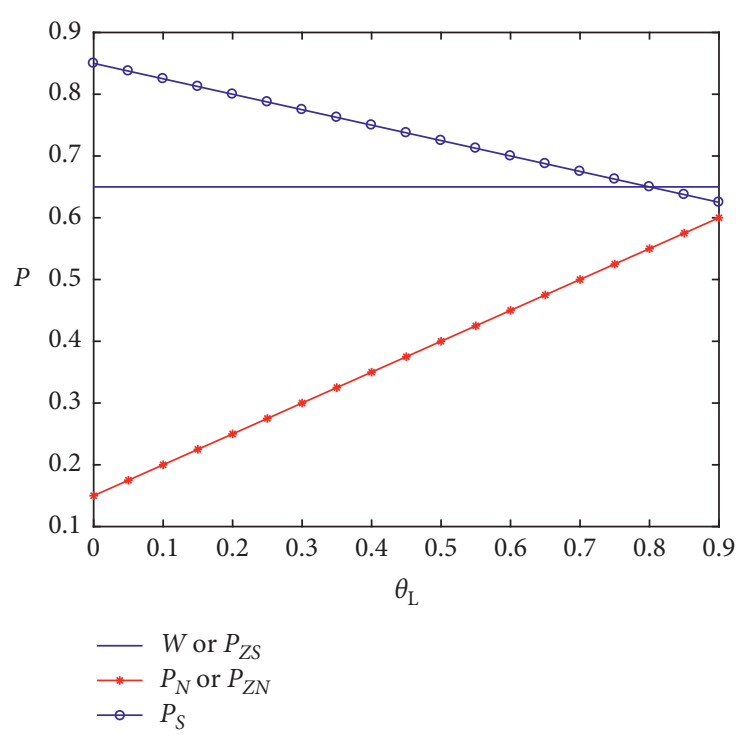

(a)

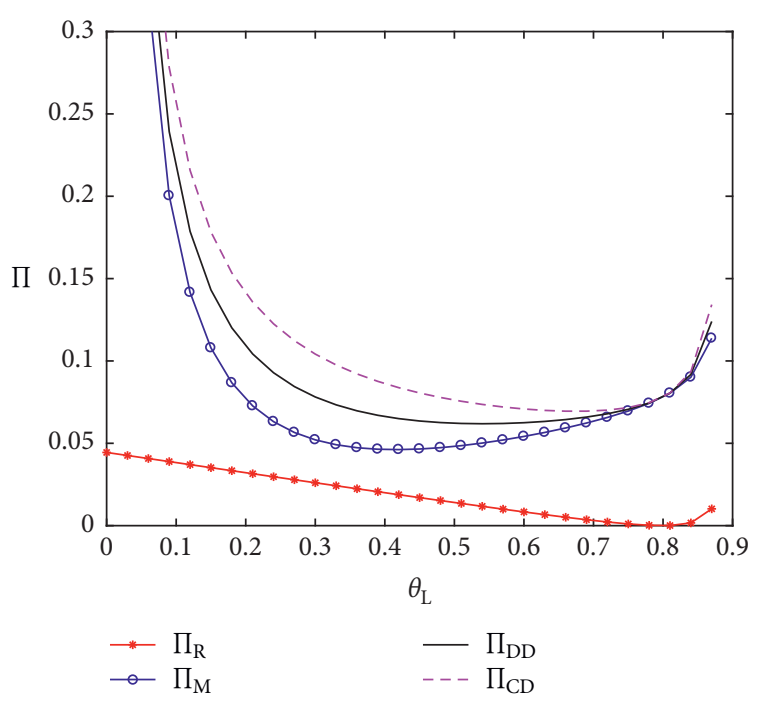

(b)

Figure 10: The influence of parameter $\theta_{L}$ on optimal decisions.

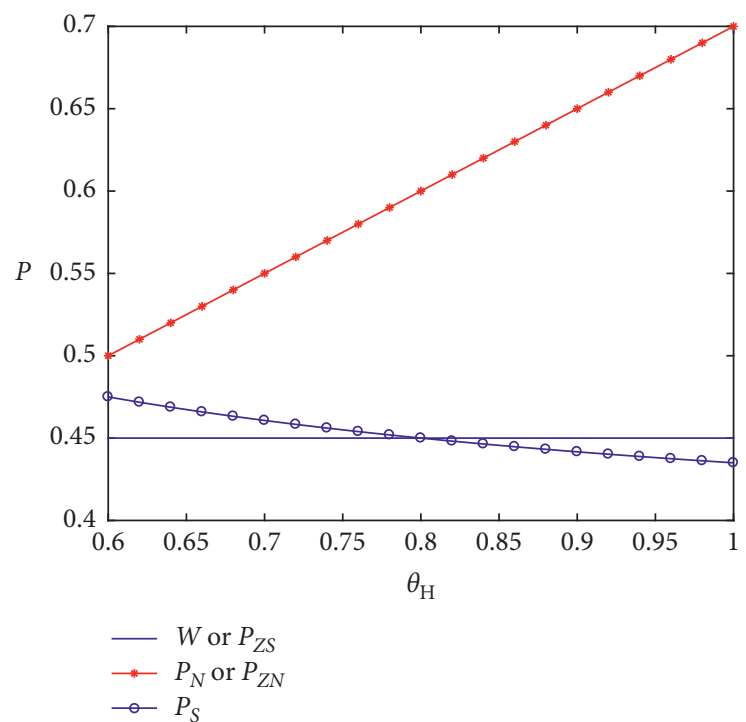

(a)

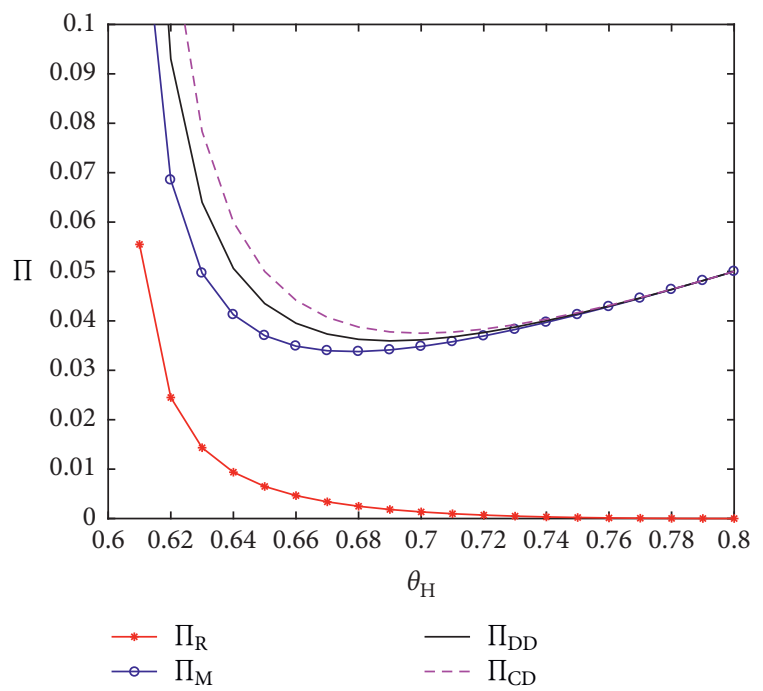

(b)

Figure 11: The influence of parameter $\theta_{H}$ on optimal decisions.

Similarly, according to Lemma 5, we can get the range of parameter $\theta_{L}$ is $0.68<\theta_{L}<0.84$. In this interval, the optimal prices have following relationship: $P_{\mathrm{N}}^{L H^{*}}>P_{\mathrm{S}}^{L H^{*}}>W^{L^{*}}$. The sale price of higher performance products in the electronic channel is significantly more than the sale price of lower performance products in the retail channel, while the price of the retail channel is slightly higher than wholesale price $W^{L^{*}}$; and the manufacturer profit is higher than the retailer profit. As the parameter $\theta_{L}$ increases, $P_{\mathrm{S}}^{L H^{*}}$ and $W^{L^{*}}$ increase, but $P_{\mathrm{N}}^{L H^{*}}$ remains the same; all of the profit functions increase, and the speed of increasing is faster and faster. When the value of the parameter $\theta_{L}$ exceeds 0.8 , the retailer profit increases from zero, and the total profit of centralized decision is slightly higher than the total profit of decentralized decision.

Based on the analysis shown above, we find that the retailer profits of model I is more than that of model II, and the retailer profits is almost zero in model II. Although the manufacturer is the leader, it needs to take into account the retailer profits. Therefore, the manufacturer selects model II, i.e., sell higher performance products in the retail channel, and sell lower performance products in the electronic channel. 


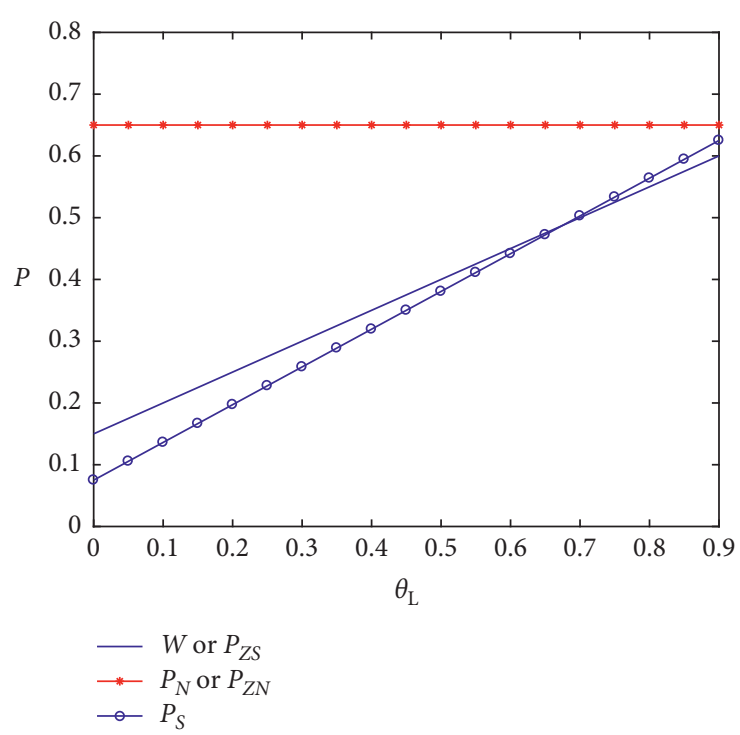

(a)

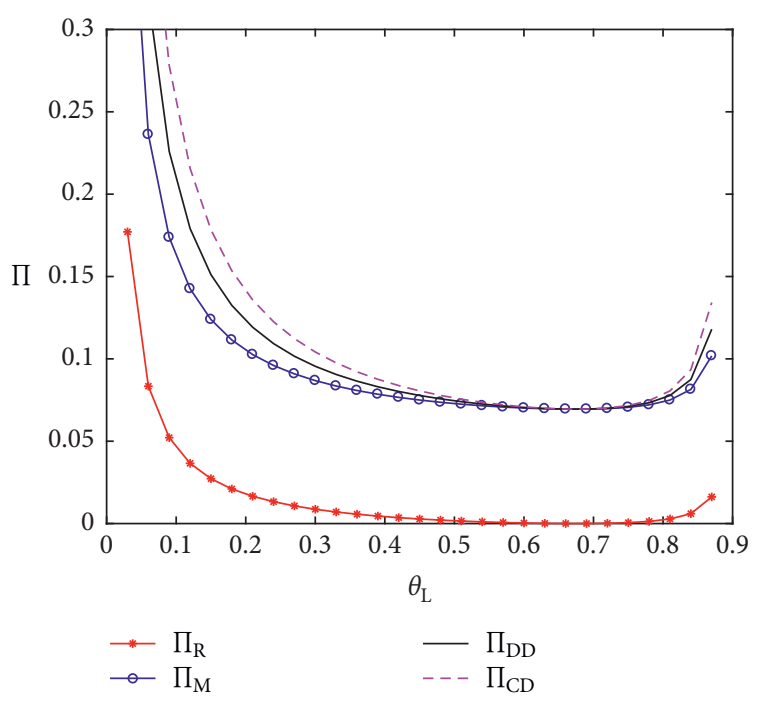

(b)

Figure 12: The influence of parameter $\theta_{L}$ on optimal decisions.

\section{Conclusions and Managerial Implications}

Based on the supply chain selling two differentiated products, this paper discusses optimal prices for the manufacturer and the retailer, in the single retail channel and dualchannel supply chains, respectively. Then, we can get the influence of parameters on optimal prices and optimal profit by numerical analysis. We identify five important managerial implications as follows:

First, in model I and model II, when WTP is close to 1, the best choice for strategic customers is to buy the higher performance products. When WTP nears zero, strategic customers will leave the market.

Second, in the single retail channel and dual-channel supply-chain model I, if the manufacturer wants to expand the product demand, it needs to improve the satisfaction of strategic customers about lower performance products $\theta_{L}$. While the satisfaction of strategic customers about higher performance products $\theta_{H}$ is increasing, the product demand remains the same, i.e., some strategic customers who buy the lower performance products change to buy the higher performance products.

Third, in the dual-channel supply-chain model II, when the supply chain is decentralized, the manufacturer needs to improve the satisfaction of strategic customers with higher performance products $\theta_{H}$ or with lower performance products $\theta_{L}$ to expand the product demand. But when the supply chain is centralized, the manufacturer needs to increase satisfaction with lower performance products $\theta_{L}$ to expand the product demand.

Fourth, when the manufacturer is dominant in the Stackelberg model, the retailer does not want the manufacturer to open the electronic channel. Through numerical analysis, we can find that the difference between retailer profit and manufacturer profit in the single retail channel is less than that in the dual channel. Once the manufacturer decides to open an electronic channel, i.e., adopt a dual-channel strategy, the retailer wants to sell the higher performance products rather than the lower performance products because the retailer profit is almost zero in dual-channel model II.

Fifth, in dual-channel model I, the satisfaction of strategic customers with higher performance products $\theta_{H}$ is higher and the parameter $\theta_{L}$ is lower, and then the retailer can get more benefits.

Based on the above conclusion, we can get that if the manufacturer wants to expand the product demand in the single traditional channel and dual-channel model I, the key is to improve the satisfaction of lower performance products $\theta_{L}$. While there are two cases in the dual-channel model I, if the decision is decentralized, the manufacturer should improve the satisfaction of higher performance products $\theta_{H}$ or the satisfaction of lower performance products $\theta_{L}$ to expand the product demand, and if the decision is centralized, the manufacturer can only expand the market demand by improving the satisfaction of lower performance products $\theta_{L}$. From the perspective of enterprise profit, the retailer does not want the dominated manufacturer to open electronic channels. If the manufacturer must open electronic channels, the retailer also wants to use dual-channel model I. If the manufacturer adopts dual-channel model II, the parameter $\theta_{H}$ is higher and $\theta_{L}$ is lower, and the profits of the retailer are higher.

In this paper, our study considers all customers are strategic; actually, the customers own individual differences, so the customers are not all strategic in a real market. Further research is needed in this area. In addition, we assume that the retail channel sells one kind of product, while the electronic channel sells another kind of product. The effects of selling two kinds of differentiated products in every channel simultaneously should be researched. 


\section{Data Availability}

The data used in our numerical experiments are taken randomly, and all used data released in this paper can be used directly.

\section{Conflicts of Interest}

The authors declare that they have no conflicts of interest.

\section{Acknowledgments}

This work was supported by the National Natural Science Foundation of China (Project nos. 71571151, 71871197, and 71872158), Shandong Provincial Natural Science Foundation (Project nos. ZR2017BG017 and ZR2017MG001), Fujian Natural Science Foundation (Project no. 2018J05117), Fujian Social Science Foundation (Project no. FJ2017C014), and Project of Humanities and Social Sciences (Project no. 17YJA630083).

\section{References}

[1] H.-C. Chiu, Y.-C. Hsieh, J. Roan, K.-J. Tseng, and J.-K. Hsieh, "The challenge for multichannel services: cross-channel freeriding behavior," Electronic Commerce Research and Applications, vol. 10, no. 2, pp. 268-277, 2011.

[2] X. Ai, J. Ma, Z. Chen, and X. Tang, "Coordination mechanism of E-channel and traditional channel under service freeriding," Journal of Systems Engineering, vol. 26, no. 4, pp. 507-514, 2011.

[3] L. Fanti and L. Gori, "The dynamics of a differentiated duopoly with quantity competition," Economic Modelling, vol. 29, no. 2, pp. 421-427, 2012.

[4] J. Zhang, Q. Da, and Y. Wang, "Retraction notice to "Analysis of nonlinear duopoly game with heterogeneous players" [Econ. Model 1. 24 (2007) 138-148]," Economic Modelling, vol. 41, p. 435, 2014.

[5] P. Bougette, "Preventing merger unilateral effects: a NashCournot approach to asset divestitures," Research in Economics, vol. 64, no. 3, pp. 162-174, 2010.

[6] J. J. Gabszewicz and J. F. Thisse, "Price competition, quality and income disparities," Journal of Economic Theory, vol. 20, no. 3, pp. 340-359, 1979.

[7] A. Shaked and J. Sutton, "Relaxing price competition through product differentiation," The Review of Economic Studies, vol. 49, no. 1, pp. 3-13, 1982.

[8] K. S. Moorthy and I. P. L. Png, "Market segmentation, cannibalization, and the timing of product introductions," Management Science, vol. 38, no. 3, pp. 345-359, 1992.

[9] W. Amaldoss and W. Shin, "Competing for low-end markets," Management Science, vol. 30, no. 5, pp. 776-788, 2011.

[10] M. Pedram and S. Balachander, "Increasing quality sequence: when is it an optimal product introduction strategy?," Management Science, vol. 61, no. 10, pp. 2487-2494, 2014.

[11] D. Y. Zhao, H. Y. Gu, and C. Liu, "Price competition and strategy of product differential location: game theory and its extension," Journal of Management Science in China, vol. 9, no. 5, pp. 1-7, 2006.

[12] Q. Liu and D. Zhang, "Dynamic pricing competition with strategic customers under vertical product differentiation," Management Science, vol. 59, no. 1, pp. 84-101, 2013.
[13] S.-W. Kim and P. C. Bell, "Optimal pricing and production decisions in the presence of symmetrical and asymmetrical substitution," Omega, vol. 39, no. 5, pp. 528-538, 2011.

[14] R. Yan, "Product brand differentiation and dual-channel store performances of a multi-channel retailer," European Journal of Marketing, vol. 44, no. 5, pp. 672-692, 2010.

[15] Y. G. Chen and N. Liu, "Coordination of dual-channel supply chain under product differentiation," Journal of Industrial Engineering Management, vol. 25, no. 2, pp. 239-244, 2011.

[16] J. Andaluz and G. Jarne, "On the dynamics of economic games based on product differentiation," Mathematics and Computers in Simulation, vol. 113, pp. 16-27, 2015.

[17] J. Freyberger, "Asymptotic theory for differentiated products demand models with many markets," Journal of Econometrics, vol. 185, no. 1, pp. 162-181, 2015.

[18] J. Chen, L. Liang, D.-Q. Yao, and S. Sun, "Price and quality decisions in dual-channel supply chains," European Journal of Operational Research, vol. 259, no. 3, pp. 935-948, 2017.

[19] H. Huang, Y. He, and J. Chen, "Competitive strategies and quality to counter parallel importation in global market," Omega, vol. 86, pp. 173-197, 2019.

[20] S. U. Kucuk and R. C. Maddux, "The role of the Internet on free-riding: an exploratory study of the wallpaper industry," Journal of Retailing and Consumer Services, vol. 17, no. 4, pp. 313-320, 2010.

[21] R. P. Cubitt, M. Drouvelis, S. Gächter, and R. Kabalin, "Moral judgments in social dilemmas: how bad is free riding?," Journal of Public Economics, vol. 95, no. 3-4, pp. 253-264, 2011.

[22] A. Ertan, T. Page, and L. Putterman, "Who to punish? Individual decisions and majority rule in mitigating the free rider problem," European Economic Review, vol. 53, no. 5, pp. $495-511,2009$.

[23] J. C. Coats, T. J. Gronberg, and B. Grosskopf, "Simultaneous versus sequential public good provision and the role of refunds - an experimental study," Journal of Public Economics, vol. 93, no. 1-2, pp. 326-335, 2009.

[24] T. Kiyonari and P. Barclay, "Cooperation in social dilemmas: free riding may be thwarted by second-order reward rather than by punishment," Journal of Personality and Social Psychology, vol. 95, no. 4, pp. 826-842, 2008.

[25] Z. Ding and Y. Liu, "Revenue sharing contract in dual channel supply chain in case of free riding," Journal of Systems Engineering, vol. 28, no. 3, pp. 370-376, 2013.

[26] S. Huang and C. Yang, "Optimal pricing and capacity choice model with strategic customer behavior," Operations Research and Management Science, vol. 23, no. 3, pp. 16-24, 2014.

[27] G. B. Bi, Y. X. Wang, and J. J. Ding, "Dynamic pricing based on substitutes and strategic consumers," Journal of Systems Engineering, vol. 28, no. 1, pp. 47-54, 2013.

[28] G. Li and F. Wei, "Strategic consumer behavior and price guarantees in supply chain coordination," Chinese Journal of Management, vol. 10, no. 2, pp. 225-232, 2013.

[29] J. Correa, R. Montoya, and C. Thraves, "Contingent preannounced pricing policies with strategic consumers," Operations Research, vol. 64, no. 1, pp. 251-272, 2016.

[30] G. J. Ji, L. Zhang, G. Y. Yang, and Y. Xu, "Supply chain performance under different power structures based on strategic customer behavior," Control and Decision, vol. 31, no. 3, pp. 458-466, 2016.

[31] Z. S. Chen, "Supply chain coordination with strategic consumer behavior under the perspective of prospect theory," Journal of Industrial Engineering Management, vol. 31, no. 4, pp. 93-100, 2017. 
[32] F. L. Zhang, Y. Zhang, and X. L. Xu, "Retailer's return policy based on strategic consumer behavior," Journal of Management Science in China, vol. 20, no. 11, pp. 100-113, 2017.

[33] A. K. Parlakuerk, "The value of product variety when selling to strategic consumers," Manufacturing \& Service Operations Management, vol. 14, no. 3, pp. 371-385, 2012.

[34] G. Y. Yang and G. J. Ji, "Entry deterrence strategy when selling to strategic consumers," Chinese Journal of Management Science, vol. 23, no. 11, pp. 153-162, 2015.

[35] F. Bernstein, J.-S. Song, and X. Zheng, "Free riding in a multichannel supply chain," Naval Research Logistics, vol. 56, no. 8, pp. 745-765, 2009. 


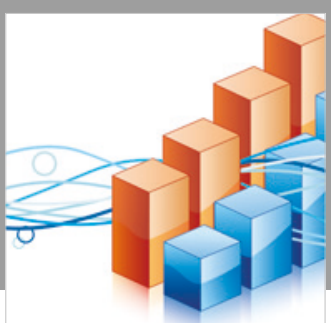

Advances in

Operations Research

\section{-n-m}
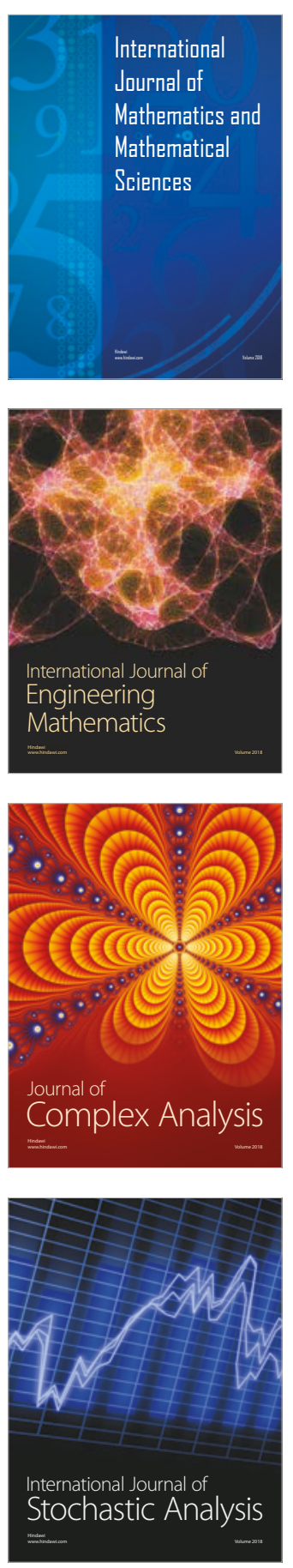
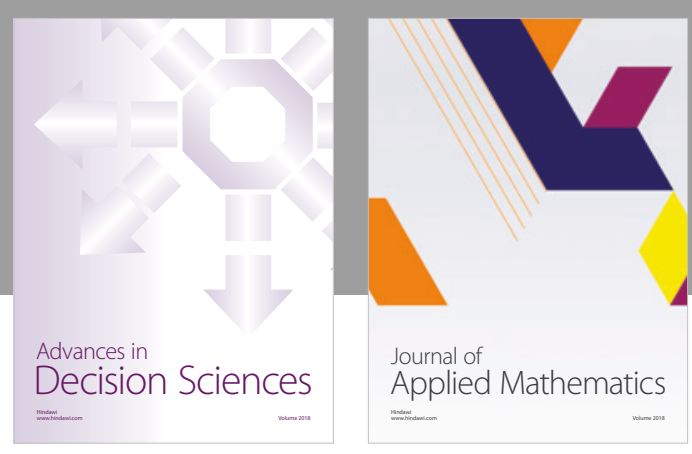

Journal of

Applied Mathematics
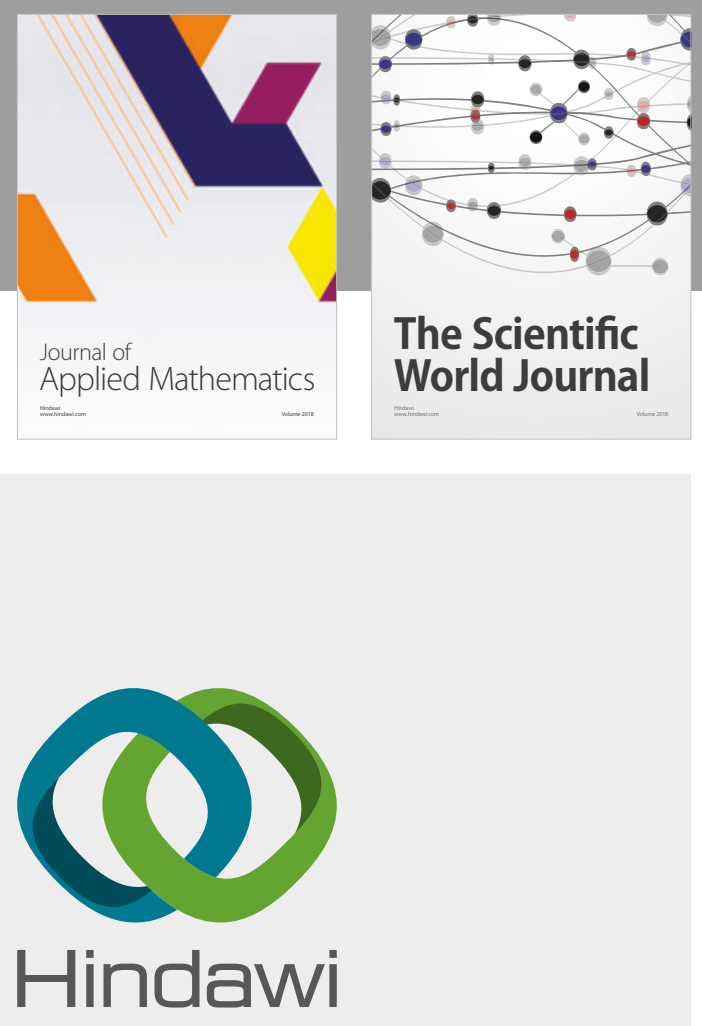

Submit your manuscripts at

www.hindawi.com

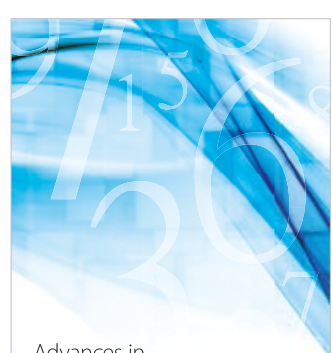

Advances in
Numerical Analysis
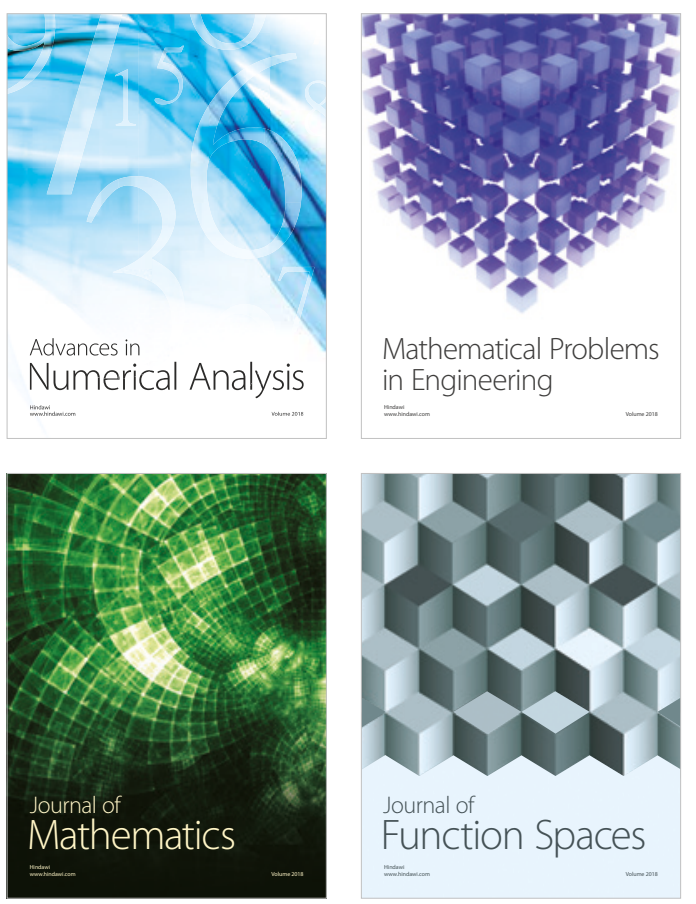

Mathematical Problems in Engineering

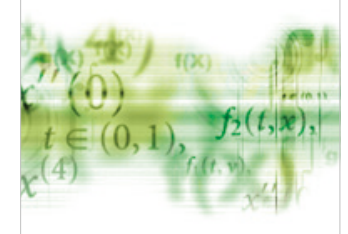

International Journal of

Differential Equations

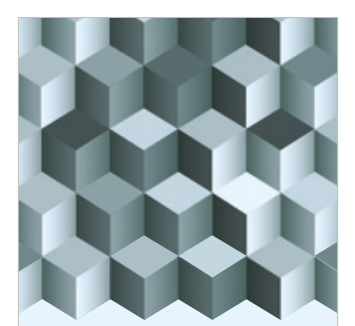

Journal of

Function Spaces

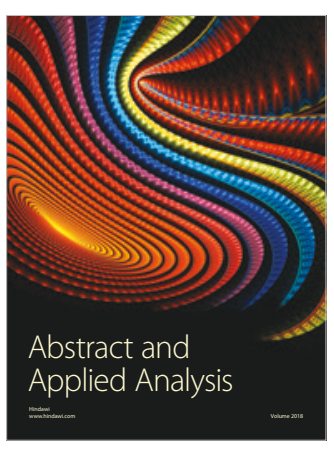

The Scientific

World Journal

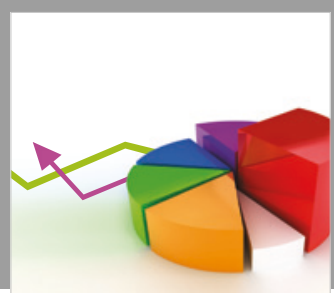

Journal of

Probability and Statistics
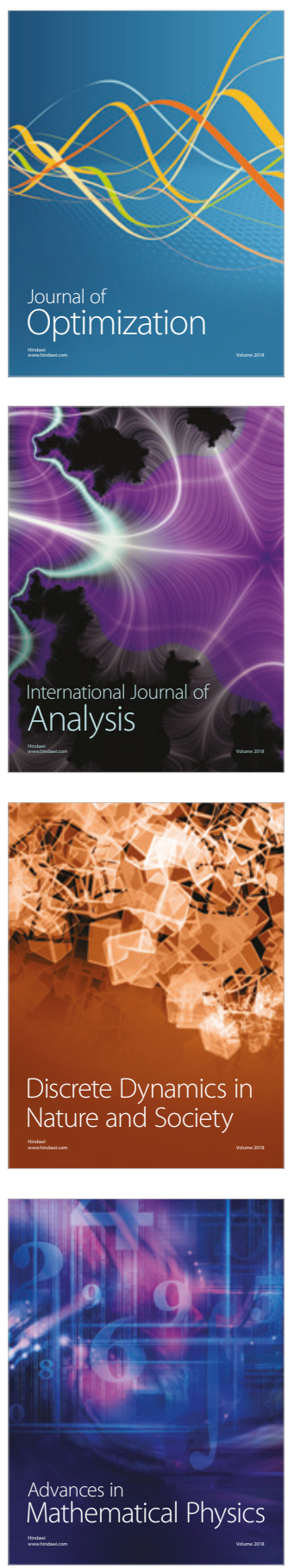